\title{
Inhibition of chemerin/CMKLR1 axis in neuroblastoma cells reduces clonogenicity and cell viability in vitro and impairs tumor growth in vivo
}

\author{
Conny Tümmler ${ }^{1}$, Igor Snapkov ${ }^{1}$, Malin Wickström² ${ }^{2}$ Ugo Moens ${ }^{1}$, Linda Ljungblad ${ }^{2}$, \\ Lotta Helena Maria Elfman ${ }^{2}$, Jan-Olof Winberg ${ }^{3}$, Per Kogner ${ }^{2}$, John Inge Johnsen ${ }^{2}$ \\ and Baldur Sveinbjørnsson ${ }^{1,2}$

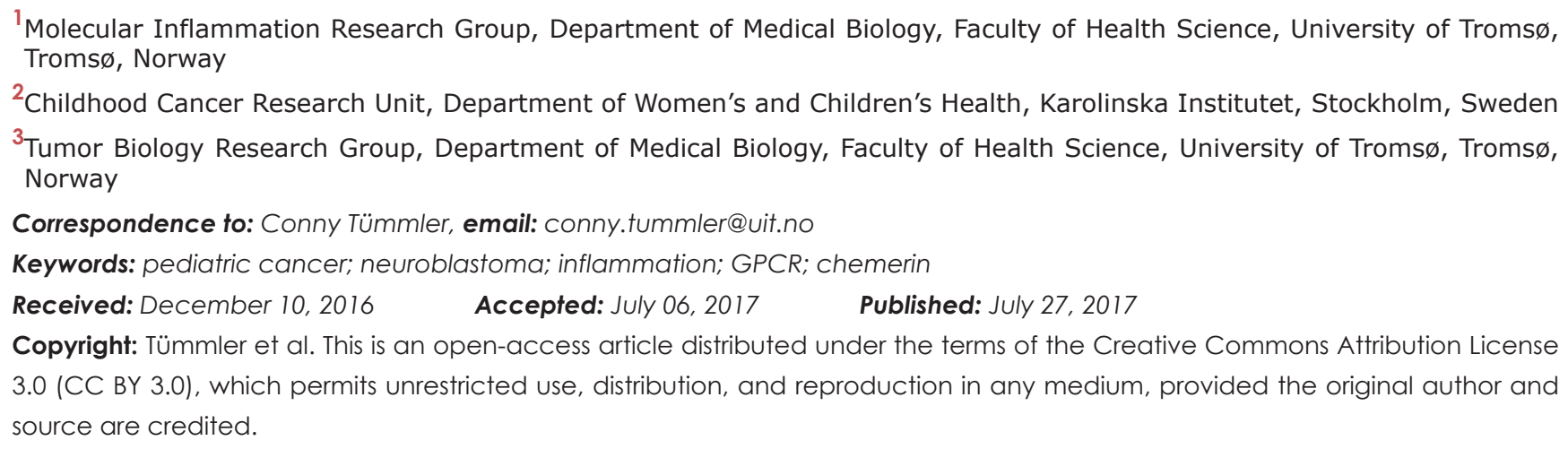

\section{ABSTRACT}

Pro-inflammatory cells, cytokines, and chemokines are essential in promoting a tumor supporting microenvironment. Chemerin is a chemotactic protein and a natural ligand for the receptors CMKLR1, GPR1, and CCRL2. The chemerin/CMKLR1 axis is involved in immunity and inflammation, and it has also been implicated in obesity and cancer.

In neuroblastoma, a childhood tumor of the peripheral nervous system we identified correlations between high CMKLR1 and GPR1 expression and reduced overall survival probability. CMKLR1, GPR1, and chemerin RNA and protein were detected in neuroblastoma cell lines and neuroblastoma primary tumor tissue. Chemerin induced calcium mobilization, increased MMP-2 synthesis as well as MAP-kinase- and Aktmediated signaling in neuroblastoma cells. Stimulation of neuroblastoma cells with serum, TNF $\alpha$ or IL-1 $\beta$ increased chemerin secretion. The small molecule CMKLR1 antagonist $\alpha$-NETA reduced the clonogenicity and viability of neuroblastoma cell lines indicating the chemerin/CMKLR1 axis as a promoting factor in neuroblastoma tumorigenesis. Furthermore, nude mice carrying neuroblastoma SK-N-AS cells as xenografts showed impaired tumor growth when treated daily with $\alpha$-NETA from day 1 after tumor cell injection.

This study demonstrates the potential of the chemerin/CMKLR1 axis as a prognostic factor and possible therapeutic target in neuroblastoma.

\section{INTRODUCTION}

Neuroblastoma is a malignancy of the sympathetic nervous system occurring in early childhood and accounting for $7 \%$ of all pediatric cancers [1]. While the prognosis for low and intermediate risk neuroblastoma patients is favorable, the long-term event-free survival rate for high-risk patients remains less than $50 \%$, despite intensive treatment $[1,2]$.
Chronic inflammation is an important modulator of the tumor microenvironment (TME). Pro-inflammatory cells, cytokines, and chemokines present in the TME promote tumor development, progression, and metastasis in various cancers $[3,4]$. Recently, a subset of highrisk, therapy-resistant neuroblastomas was demonstrated to be inflammation-driven indicating the importance of inflammation in neuroblastoma [5]. A thorough understanding of the neuroblastoma TME and the 
inflammatory processes involved in tumorigenesis may lead to new therapy approaches and the discovery of novel prognostic markers [6-9].

Chemerin (also known as TIG-2 or RARRES2) is an adipokine and chemoattractant factor associated with obesity, inflammatory diseases and cancer [1020]. Synthesized as a 163 amino acid preproprotein, this chemerin precursor is N-terminally cleaved and secreted as prochemerin with low activity. Following secretion, prochemerin can be C-terminally cleaved by a variety of extracellular proteases, resulting in several chemerin isoforms with varying length, receptor affinity, and biological activity [21]. Proteases associated with inflammation such as cathepsin $\mathrm{G}$ and neutrophil elastase respectively cleave prochemerin into chemerin 21-156 and 21-157. These are the most active forms, whereas prochemerin processed with mast cell chymase or protease 3 results in the inactive or low activity chemerin 21-154 and 21-155 variants, respectively [22, 23]. During inflammation initiation, maintenance and resolution the different chemerin isoforms may exert pro- and/or anti-inflammatory functions $[24,25]$. Chemerin is a natural ligand for the G-protein-coupled receptors CMKLR1 (or ChemR23), GPR1, and CCRL2. CMKLR1 is expressed by different cell types including macrophages as well as immature dendritic cells and mediates the majority of the described chemerin functions [10, 24, 26-29]. Besides the involvement in various inflammatory diseases, the chemerin/CMKLR1 axis has been shown to play a role in different malignancies. While there is evidence that chemerin and CMKLR1 support tumorigenesis in glioblastoma, gastric cancer, squamous esophageal cancer and squamous cell carcinoma of the oral tongue [16-18, 20], an anti-tumorigenic effect has been suggested in melanoma, hepatocellular carcinoma and non-small cell lung cancer [15, 30, 31].

GPR1 functions are so far less understood, but it has recently been found to contribute to the regulation of glucose homeostasis in obese mice [32]. At present, no active signaling has been detected following chemerin binding to CCRL2. However, CCRL2 is known to increase local chemerin concentrations [33] and its expression has been linked to rheumatoid arthritis and liver metastasis in colorectal cancer $[34,35]$. The aim of the present study was to investigate the functional significance of chemerin, CMKLR1 and GPR1 in the neuroblastoma microenvironment and assess their potential as prognostic factors and therapeutic targets.

\section{RESULTS}

\section{High CMKLR1 and GPR1 expression predict poor overall survival probability in neuroblastoma}

To investigate CMKLR1 and GPR1 gene expression in neuroblastoma we used the publically available R2: Genomics analysis and visualization platform http:// r2.amc.nl. Examining two neuroblastoma gene expression cohorts, we found a correlation between high expression of CMKLR1 (Figure 1A and 1B) and GPR1 (Figure 1D and $1 \mathrm{E}$ ) and a decrease in overall survival probability. Furthermore, CMKLR1 expression was higher in neuroblastoma cohorts compared to benign neurofibroma and neural crest cells (Figure 1C). However, no difference was found comparing GPRI expression in the different cohorts (Figure 1F).

Additionally, we observed that expression of chemerin receptor CCRL2 was elevated in the neuroblastoma cohorts compared to neurofibroma and neural crest, and that high expression of CCRL2 correlated with a poor survival prognosis (Supplementary Figure 1D1F). While chemerin (RARRES2) expression was higher in the neuroblastoma cohorts compared to the neural crest, no difference was seen in comparison with benign neurofibroma. Furthermore, no clear correlation between high expression of RARRES2 and a decrease in overall survival probability was apparent due to conflicting results in the selected data sets (Supplementary Figure 1A-1C).

\section{Neuroblastoma cell lines express chemerin, CMKLR1 and GPR1}

We examined different neuroblastoma cell lines for the expression of CMKLR1, GPR1 and chemerin. Using RT-PCR (Figure 2A) and western blot (Figure 2B) we demonstrated expression of CMKLR1, GPR1 and chemerin mRNA and protein at varying levels in all neuroblastoma cell lines tested. No correlation was apparent between CMKLR1, GPR1 or chemerin expression levels and specific cell line characteristics such as MYCN amplification, 1p deletion, 11q deletion or multidrug resistance phenotype.

HepG2 cells were included in the western blots as a positive control. They are known to express and secrete chemerin and several antibody suppliers recommended them as a control cell line for CMKLR1.

Furthermore, we examined the expression levels of RARRES2 (chemerin), CMKLR1 and GPR1 in a panel of neuroblastoma cell lines using the publically available R2: Genomics analysis and visualization platform http://r2.amc.nl. We observed that all three genes are expressed at varying levels in the neuroblastoma cell lines included in this panel (Supplementary Figure 2A2C). In addition we compared their expression to known neuroblastoma promoting cytokines, chemokines, growth factors and their receptors and found GPRI and CMKLR1 expression in the range of FPR1, IL6R and PDGFRA. While RARRES2 (chemerin) expression is lower than $V E G F A$, it is comparable to CCL2 and CCL5 expression (Supplementary Figure 2D and 2E).

Immunofluorescence staining demonstrated the cellular distribution of CMKLR1 (Figure 2C) and GPR1 (Figure 2D) in the neuroblastoma cell line SH-SY5Y. Both receptors were localized at the cell membrane 
and in the cytoplasm. Comparable staining pattern for CMKLR1 was observed in other neuroblastoma cell lines using additional primary antibodies for confirmation (Supplementary Figure 3A and 3B). No apparent staining was observed in cells incubated with an isotype control antibody instead of the primary antibody (Supplementary Figure 3C).

\section{TNF $\alpha$, IL-1 $\beta$ and serum increase chemerin secretion in neuroblastoma cells}

To investigate the effect of the pro-inflammatory cytokines TNF $\alpha$ and IL- $1 \beta$ as well as serum components on chemerin expression and secretion, chemerin concentrations were measured by ELISA. Exposure to IL- $1 \beta$, TNF $\alpha$ as well as $10 \%$ serum for $24 \mathrm{~h}$ increased the level of chemerin in the supernatant of SK-N-AS cells (Figure 2E).

\section{CMKLR1, GPR1 and chemerin are expressed in neuroblastoma primary tumors}

To confirm the presence of CMKLR1, GPR1 and chemerin in neuroblastoma primary tumors, IHC and IF-P were performed. A total of 27 neuroblastoma tissue samples from all clinical stages and biological subsets [36] were stained with antibodies detecting chemerin, CMKLR1 and GPR1. All tumor samples investigated demonstrated a significant expression of chemerin and its receptors. Figure 3 presents a representative labeling with CMKLR1 (Figure 3A), GPR1 (Figure 3B) and chemerin (Figure 3C) specific antibodies showing a clear staining of both the receptors and chemerin in neuroblastoma primary tumors. Fluorescence labeling of CMKLR1 (green) and chemerin (red) displayed the membranous and cytoplasmic localization of CMKLR1 whereas chemerin was detected both in intra- and extracellular compartments (Figure
A

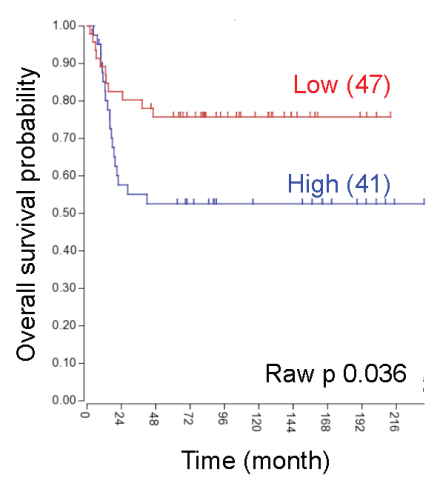

D

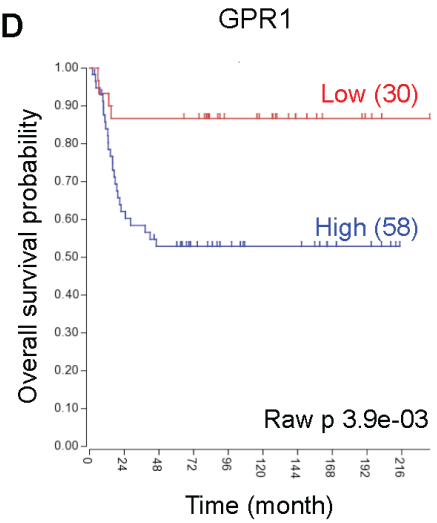

B

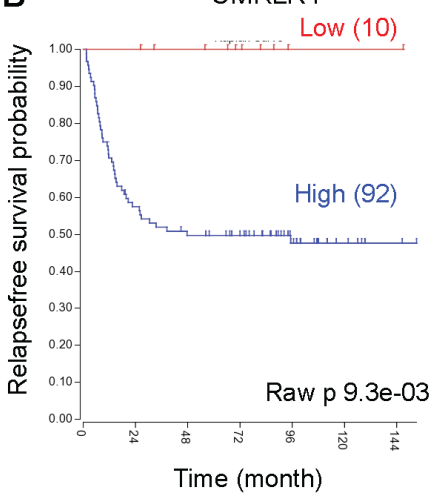

E

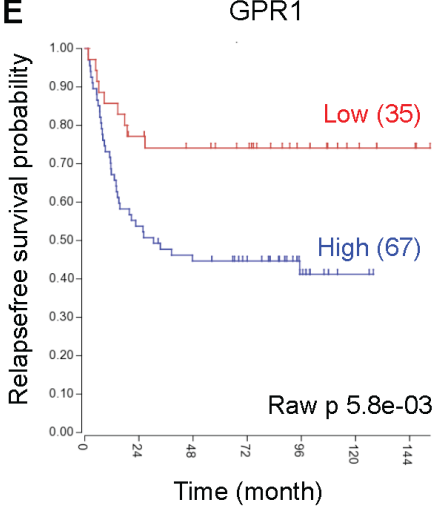

C

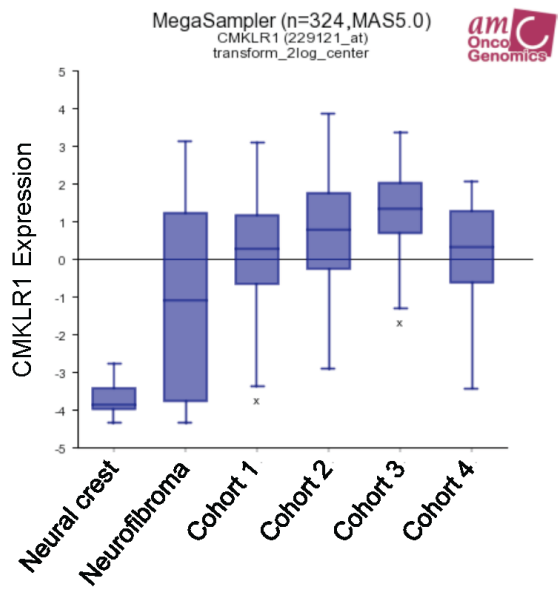

F

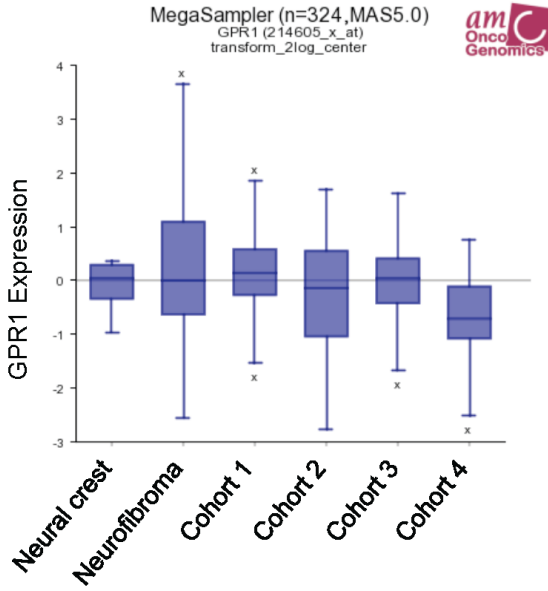

Figure 1: High CMKLR1 and GPR1 expression predicts poor survival in neuroblastoma patients. Expression data was analyzed using the R2 database http://r2.amc.nl. Kaplan-Meier survival estimates were used to evaluate the prognostic value of $C M K L R 1$ (A, B) and GPRI (D, E) expression in two patient data sets (A and D: Versteeg n=88; B and E: Seeger n=102). The Kaplan-Meier scanning tool was used to determine the CMKLR1 and GPR1 mRNA expression in neuroblastoma. All expression data were scanned to find the most optimal cut-off between high and low gene expression and the log-rank test that gave the lowest p-value was calculated to search for significant differences between tumor samples expressing high and low CMKLR1 and GPR1 mRNA levels, respectively. The expression of CMKLR1 (C) and GPRl (F) was compared between neural crest (Etchevers n=5), benign neurofibroma (Miller n=86) and 4 neuroblastoma cohorts (cohort 1: Versteeg $n=88$, cohort 2: Delattre $n=64$, cohort 3: Hiyama $n=51$, cohort 4: Lastowska $n=30$ ). 
3D-3F) indicating chemerin secretion in neuroblastoma primary tumor tissue. For both, IHC and IF-P, no apparent staining was observed in sections incubated with isotype control antibodies instead of the primary antibodies (Supplementary Figure 3D-3F).

\section{Chemerin induces calcium mobilization and promotes MAPK and Akt signaling in neuroblastoma cell lines}

Chemerin has been previously shown to stimulate intracellular calcium mobilization in immature DCs and macrophages as well as MAPK and Akt signaling in human chondrocytes and endothelial cells through CMKLR1 [14, 24, 37]. GPR1-mediated calcium mobilization and ERK1/2 phosphorylation following chemerin binding has been demonstrated to be much weaker [38, 39]. Recently, both CMKLR1 and GPR1 were found to signal through the RhoA/Rock pathway in HEK293A and gastric carcinoma cells [40].

To determine the effect of chemerin in neuroblastoma, we studied calcium mobilization, MAPK, and Akt signaling in neuroblastoma cell lines. Chemerin stimulation caused a rapid, but transient increase in intracellular calcium in SK-N-SH cells (Figure 4A and 4B) in comparison to vehicle treatment. Furthermore, prior incubation with the calcium chelator EDTA showed no inhibitory effect (Figure 4B) indicating calcium release from intracellular compartments.

The addition of chemerin to SK-N-AS cells induced a rapid and dose-dependent phosphorylation of MEK1/2, ERK1/2 and Akt (Figure 4C) indicating the activation of MAPK and Akt signaling. Similar phosphorylation patterns were observed in SK-N-BE(2) cells (data not shown).

\section{Chemerin increases MMP-2 synthesis in neuroblastoma cells}

Chemerin is known to stimulate MMP-2 and MMP-9 expression and activity [37, 41]. Using real-time zymography, we could follow the degradation of gelatin by MMP-2 and MMP-9 in real-time. We observed a dosedependent increase in MMP-2 synthesis in both SK-N-

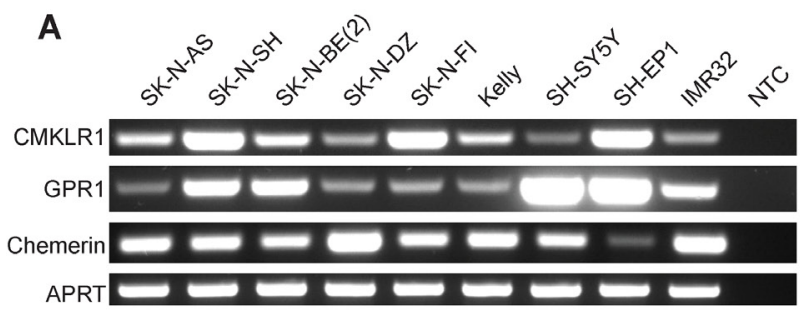

C

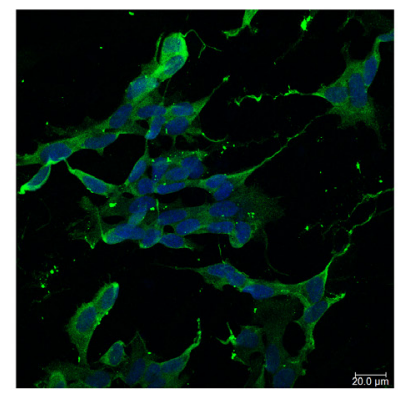

D

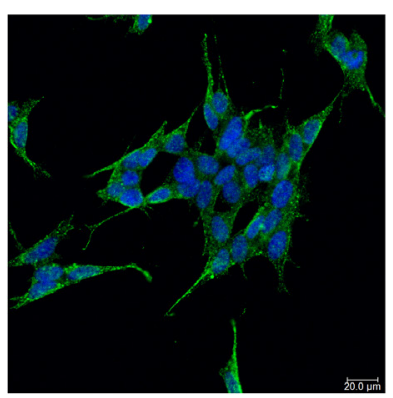

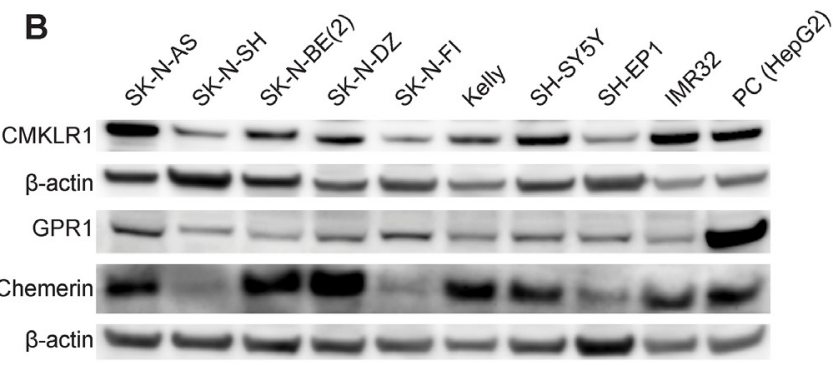

E

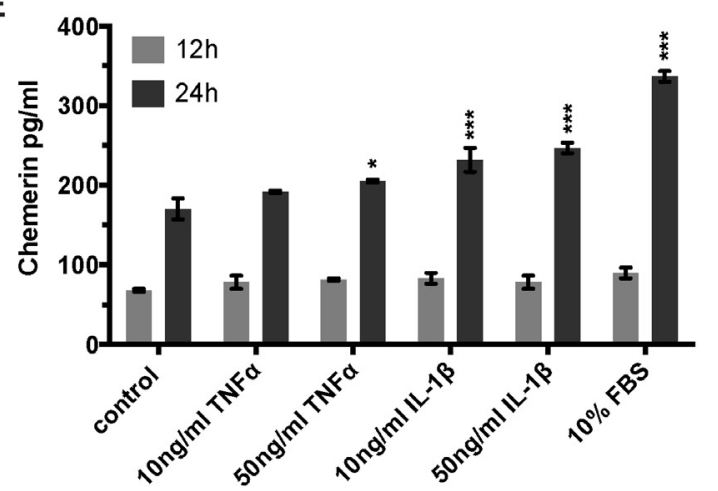

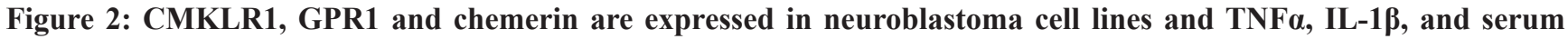
stimulate chemerin secretion. (A) RT-PCR analysis demonstrating the expression of chemerin, CMKLR1 and GPR1 mRNA in all neuroblastoma cell lines investigated. NTC, no template control. The expression of chemerin, CMKLR1, and GPR1 protein was confirmed by western blot (B). HepG2 cells were used as a positive control. The images are representative of three independent experiments. Immunofluorescence labeling shows the presence of CMKLR1 (C) and GPR1 (D) in SH-SY5Y cells (green). The nuclei (blue) were stained with Hoechst 33342, scale bar $20 \mu \mathrm{m}$. (E) Chemerin concentrations were measured in cell supernatants of SK-N-AS cells after treatment with 10 or $50 \mathrm{ng} / \mathrm{ml} \mathrm{TNF} \alpha$, IL- $1 \beta$ or $10 \%$ FBS for 12 or $24 \mathrm{~h}$, respectively. The supernatants of 10 independent samples were pooled and concentrated 10x prior to ELISA measurement. The standards and samples were measured in duplicates and the data is presented as mean and range. Statistical analysis was performed using a two-way ANOVA $\mathrm{P}<0.001$ for both stimulation and incubation time followed by Dunnett's post-test control vs. treatment ${ }^{*} \mathrm{P}<0.05,{ }^{* * *} \mathrm{P}<0.001$. 
AS and to a lesser extent in SK-N-BE(2) cells after 6, 12, 24 and $48 \mathrm{~h}$ stimulation with active chemerin (Figure 5). No effect on MMP-9 synthesis was observed under these conditions.

\section{CMKLR1 inhibition reduces the cell viability and clonogenicity of neuroblastoma cells}

The effect of CMKLR1 inhibition on neuroblastoma cell lines was studied using the recently described CMKLR1 inhibitor $\alpha$-NETA [42]. Increasing concentrations of $\alpha$-NETA reduced the cell viability of four neuroblastoma cells lines after $72 \mathrm{~h}$ of treatment with $\mathrm{IC}_{50}$ values ranging between $3.87-7.49 \mu \mathrm{M}$ (Figure 6A and $6 \mathrm{~B})$. No effect $\left(\mathrm{IC}_{50}\right.$ values $\left.>10 \mu \mathrm{M}\right)$ was observed on human fibroblasts (MRC-5) and endothelial cells (HUVEC). A dose-dependent inhibition of clonogenicity was observed in SK-N-BE(2) cells (Figure 6C) as well as SK-N-AS, SK-N-DZ, and SH-SY5Y cells (Figure 6D). The colony forming ability was completely inhibited using $5 \mu \mathrm{M} \alpha$-NETA.

\section{Early and prolonged CMKLR1 inhibition impairs neuroblastoma growth in vivo}

The therapeutic effect of CMKLR1 inhibition was examined in a SK-N-AS xenograft model. A significant prolongation ( $p=0.015$, Log rank test) of survival (defined as time needed for the animals to grow a macroscopic tumor with a volume $>1.5 \mathrm{ml}$ ) was observed in the pretreatment group, where the animals were treated s.c. with $\alpha$-NETA continuously from day 1 after tumor cell injection, compared to the control group (Figure 7). In addition, when comparing tumor growth rates for individual tumors, the tumors from the pre-treated mice grew significantly slower than the tumors in the control group $(\mathrm{p}=0.0061$, one way ANOVA with Bonferroni posttest, control vs. pre-treatment $\mathrm{p}=0.049$, Supplementary Figure 4). However, no effect was seen in the treatment group, where $\alpha$-NETA s.c. injections were initiated after the tumor reached a volume of $\geq 0.15 \mathrm{ml}$, compared to the control group. No signs of toxicity were observed at the used concentrations of $\alpha$-NETA. In the pre-treatment
A

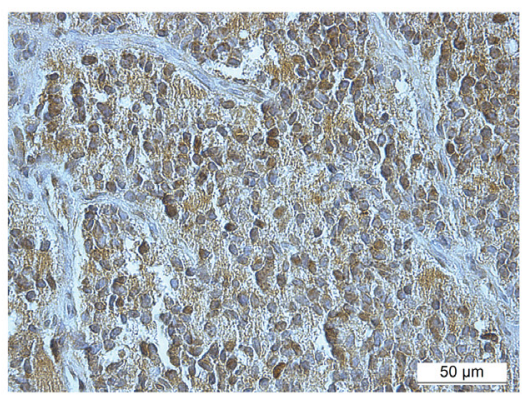

D
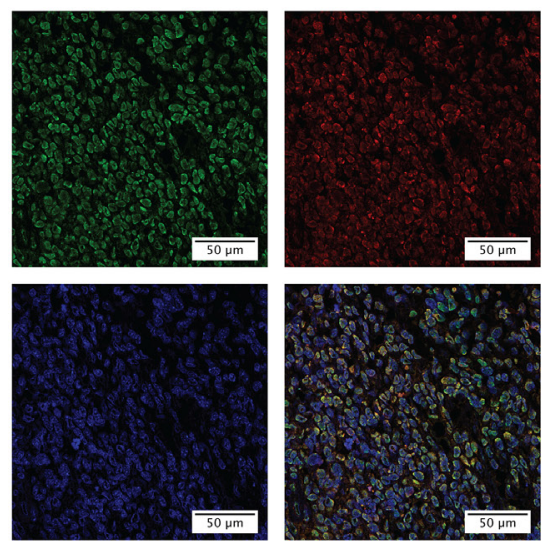

B

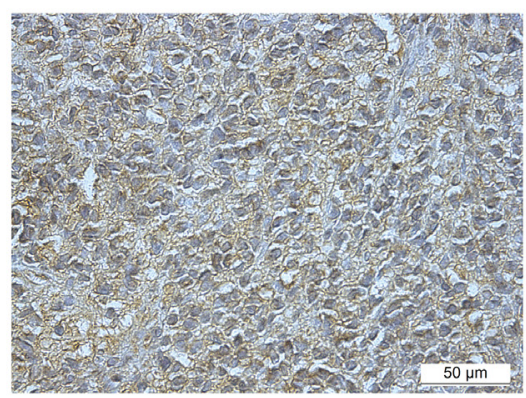

E
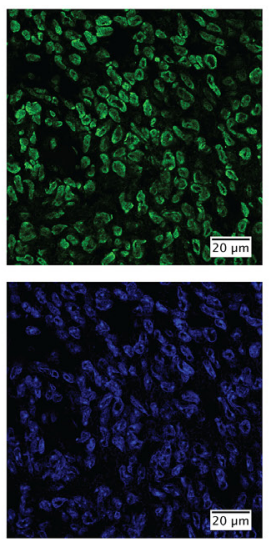

C

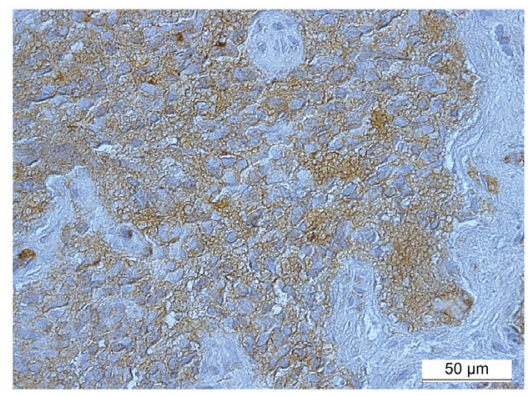

$\mathbf{F}$
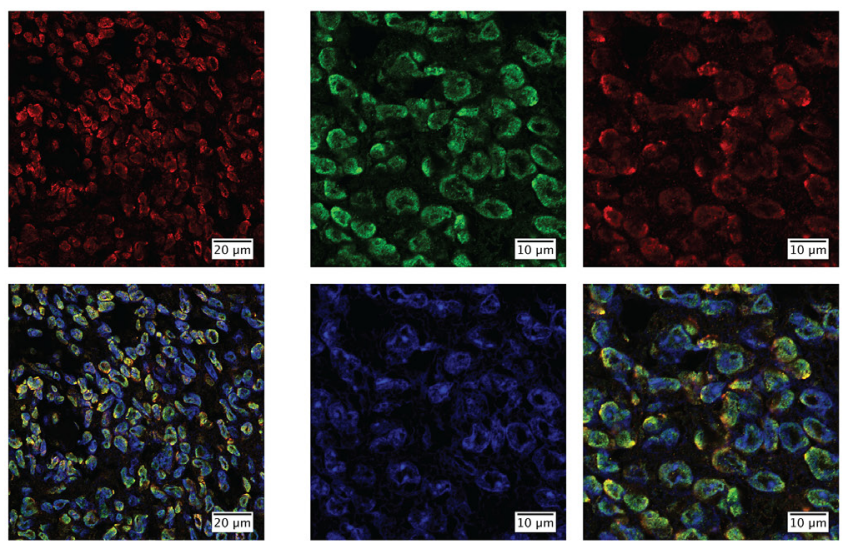

Figure 3: CMKLR1, GPR1 and chemerin are expressed in neuroblastoma primary tumors. Immunoperoxidase staining demonstrates specific expression of (A) CMKLR1, (B) GPR1 and (C) chemerin in neuroblastoma primary tumor tissue. Immunofluorescence labeling (D-F) displays CMKLR1 (green) and chemerin (red) localization in neuroblastoma tissue. The nuclei were stained with DAPI (blue). (E and F) are higher magnifications of (D) to illustrate the colocalization of CMKLR1 and chemerin. The displayed images are representative stainings from a panel of neuroblastoma tumors. 
group, a hardening of the skin was seen at the later stages of the experiment probably due to the daily s.c. injection over a prolonged period. All mice gained weight over the course of the experiment.

\section{DISCUSSION}

Neuroblastoma is a malignancy with only a few identified key genetic events. Besides amplification of the MYCN oncogene (in approximately $20 \%$ of neuroblastomas), ALK mutations and amplifications occur in $9 \%$ and $2-3 \%$, respectively. Other affected genes include ODC, NTRK2/TrkB, FOXR1, PTPN11, ATRX, $C A D M 1$, and $A R I D 1 A / B[2,43]$. For the discovery of potential new therapeutic targets, understanding of the neuroblastoma TME is of great importance. Chemokines and chemoattractant factors are essential regulators of cell trafficking during immune response and inflammation. Furthermore, they are involved in all stages of cancer development: tumor establishment, neovascularization, and metastasis [44, 45].

Several chemokine receptors and their ligands have been identified as contributors to neuroblastoma angiogenesis, metastasis, and communication between tumor cells and cells of the TME $[6,46]$. CMKLR1 is a chemoattractant receptor present on immune cells such as immature DCs, macrophages and NK cells [47]. Recently, CMKLR1 was found to be expressed in a subset of myeloid-derived suppressor cells (MDSCs) in hepatocellular carcinoma [48].

Chemerin, a ligand for CMKLR1 possesses a wide variety of characteristics attributed to tumor growth such as chemotaxis and cell adhesion, as well as cell survival and proliferation $[21,41,47]$. In ECs, CMKLR1 was
A

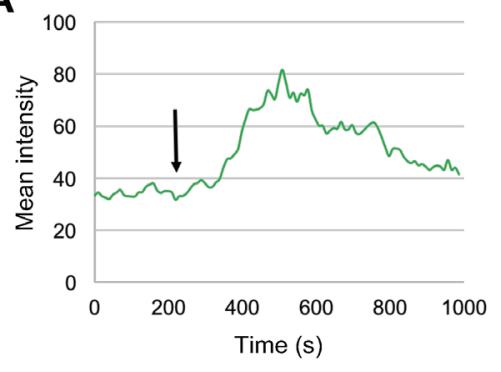

C

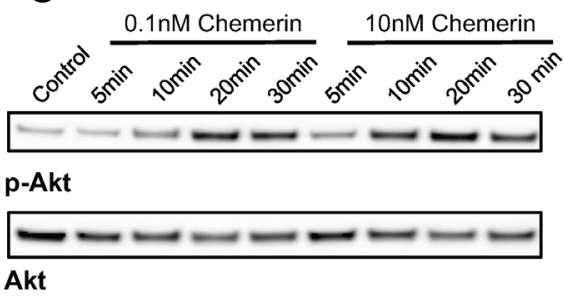

$0.1 \mathrm{nM}$ Chemerin

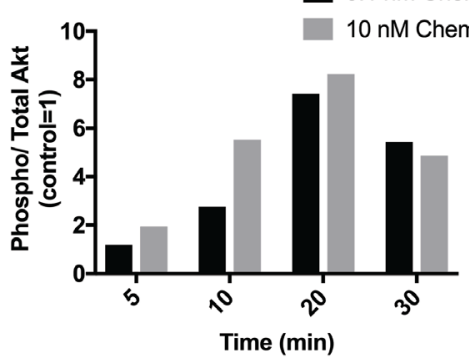

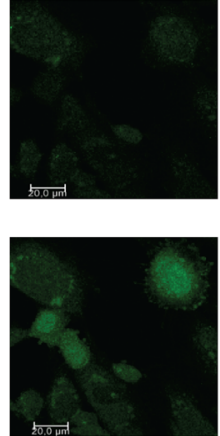

B
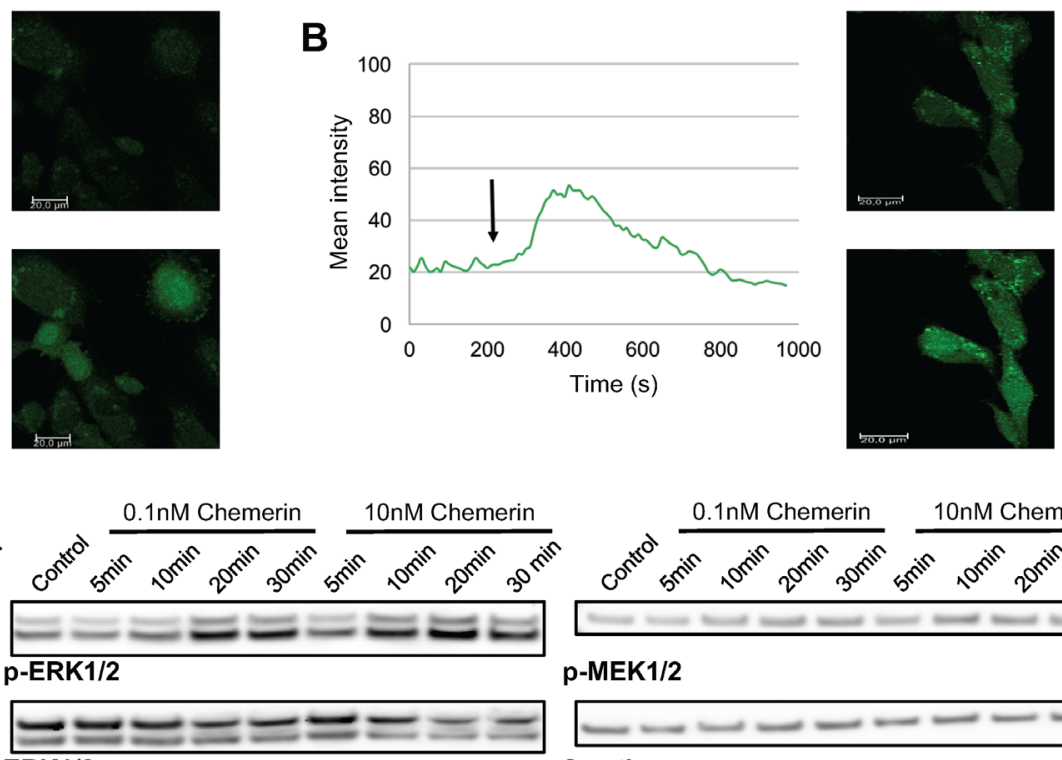
ERK1/2

$0.1 \mathrm{nM}$ Chemerin

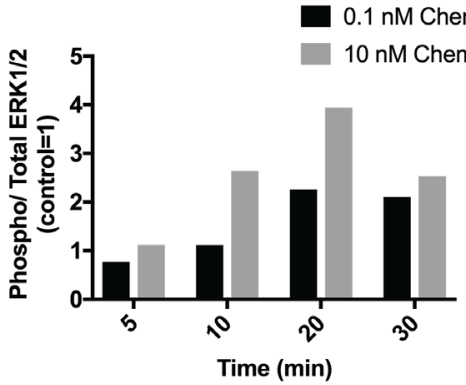

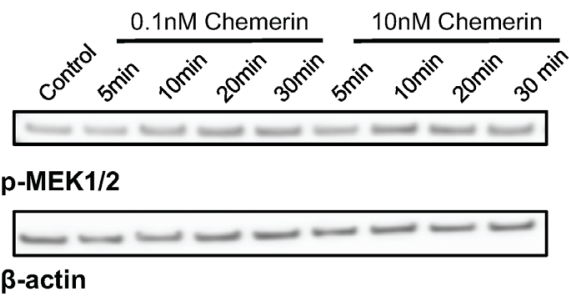

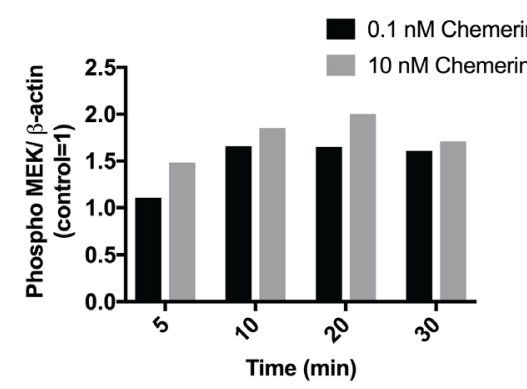

Figure 4: Chemerin induces intracellular calcium mobilization and stimulates MAPK and Akt signaling in neuroblastoma cells. Intracellular calcium mobilization was measured in SK-N-SH cells with confocal laser scanning microscopy following the stimulation with $10 \mathrm{nM}$ chemerin without (A) and with (B) the prior addition of the calcium chelator EDTA. The arrow indicates the time point when chemerin was added. (C) Chemerin stimulates the phosphorylation of Akt, ERK1/2 and MEK1/2 in SK-N-AS cells in a dose-dependent manner. The cells were serum-starved for $24 \mathrm{~h}$ prior to stimulation and samples were taken 5 , 10, 20 and $30 \mathrm{~min}$ after stimulation. Densitometric analysis of the protein bands was performed and the ratios between p-ERK1/2 and total ERK1/2, p-Akt and total Akt as well as p-MEK1/2 and $\beta$-actin were calculated. The values are displayed relative to the control=1. The experiments were performed three times with similar results. 
found to be upregulated by the pro-inflammatory cytokines TNF $\alpha$, IL-1 $\beta$ and IL-6. Furthermore, chemerin stimulation induced MMP production and angiogenesis [37]. Recent work by Chua et al. demonstrates that hypoxia promotes chemerin expression in human coronary artery endothelial cells as well as migration and tube formation, supporting previous findings on the role of chemerin in angiogenesis [49]. However, the function of the chemerin/CMKLR1 axis in malignancies is probably tumor specific as both tumor promoting and tumor suppressing roles have been reported $[15-18,20,30,31]$.

In the present study, we investigated the role of chemerin and its receptors CMKLR1 and GPR1 in neuroblastoma tumorigenesis. Using publically available gene expression datasets (http://r2.amc.nl) we observed that high CMKLR1 and GPR1 expression correlates with a reduced overall survival probability in the two datasets we examined. We did not find any relationship between genetic characteristics of neuroblastoma, such as MYCN expression, and CMKLR1, GPR1 or chemerin expression. Our findings indicate that CMKLR1 and/or GPR1 could potentially be used as independent prognostic factors.
Tumor-associated macrophages (TAMs) have been shown to promote neuroblastoma tumorigenesis [6], and CMKLR1 expression in macrophages can be stimulated by mammary and lung carcinoma cells [50]. Asgharzadeh et al. [7] described the prognostic value of a TAM gene expression signature (CD33, CD16, IL6R, IL10, FCGR3) in metastatic neuroblastoma. Examining publically available neuroblastoma gene expression datasets (R2: Genomics Analysis and Visualization Platform http://r2.amc.nl) we observed a significant correlation between expression of CMKLR1 and the TAM markers (Supplementary Figure 5). IHC labeling of the macrophage marker CD68 as well as double IF-P staining of CD68 and CMKLR1 in neuroblastoma tissue demonstrated that while the majority of CMKLR1 is expressed by the tumors cells, $\mathrm{CD}^{+} 8^{+}$cells in the TME also express CMKLR1 (Supplementary Figure 6).

Additionally, CMKLR1 is expressed at high levels in monocytic MDSCs in hepatocellular carcinoma [48]. Therefore, the expression of CMKLR1 on tumor promoting immune cells could also play a significant role in the tumorigenesis process.
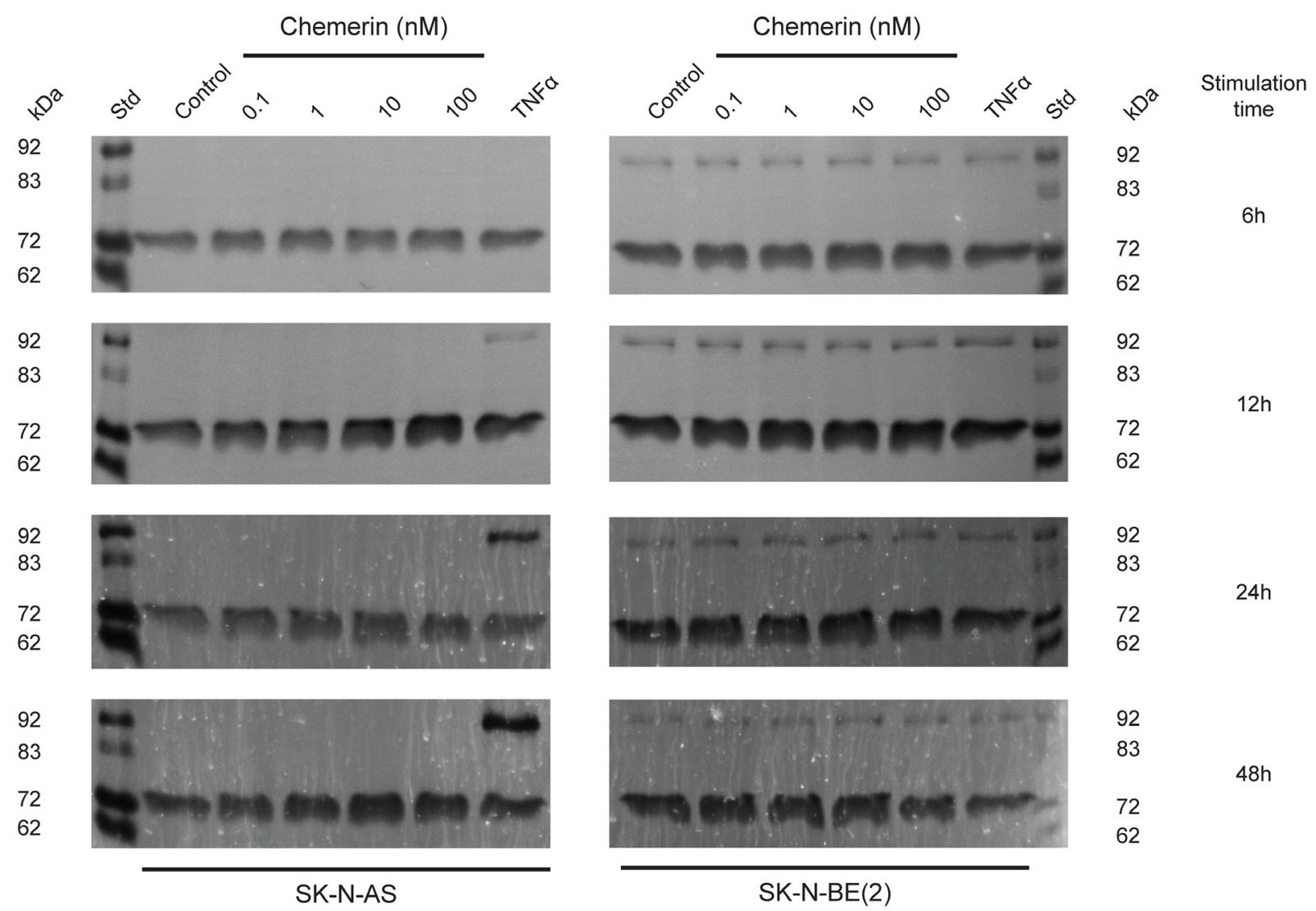

92

83

72

62

$12 \mathrm{~h}$

\section{(1)}

$48 \mathrm{~h}$

Figure 5: Chemerin stimulates MMP-2 synthesis in neuroblastoma cells. Typical real-time gelatin zymography of supernatants from SK-N-AS and SK-N-BE(2) cells untreated (control) or treated with increasing concentrations of chemerin $(0.1-100 \mathrm{nM})$ or TNF $\alpha(10$ $\mathrm{ng} / \mathrm{ml}$ ) for $6 \mathrm{~h}, 12 \mathrm{~h}, 24 \mathrm{~h}$ and $48 \mathrm{~h}$. Prior to stimulation, the cells were serum-starved for $24 \mathrm{~h}$. For each zymogram the supernatants of three independent samples were pooled and analyzed. The shown zymograms were taken after optimal incubation time (for SK-N-AS 15h, 10h, $13 \mathrm{~h}$ and $13 \mathrm{~h}$ and for SK-N-BE(2) 15h, 10h, 5h and 4h) in assay buffer after the removal of SDS from the gels. The standard (st) comprised a mixture of proMMP-9 monomer (92 kDa), active MMP-9 (83 kDa), proMMP-2 (72 kDa) and active MMP-2 (62 kDa). 
A recent study demonstrated that chemerin secreted by esophageal squamous cancer-associated myofibroblasts stimulates the migration of cancer cells, indicating a role in invasion. Blockage of the chemerin/CMKLR1 axis inhibited invasion [41]. In addition, Kaur et al. determined a mitogenic effect of chemerin on human macro- and microvascular endothelial cells through activation of CMKLR1 [37]. Therefore, a potential role of chemerin/ CMKLR1 in neuroblastoma angiogenesis could be hypothesized. Collectively, these findings indicate that targeting CMKLR1 expressed on stromal cells in addition to the tumor cells could be of therapeutic interest.

In the present study, active chemerin induced both calcium mobilization and the activation of MAPK and Akt signaling. PI3K/Akt- and MAPK-mediated signaling are known to contribute to neuroblastoma tumorigenesis [51-54]. Furthermore, we demonstrated that the pro-inflammatory cytokines TNF $\alpha$ and IL-1 $\beta$ as well as serum components stimulate chemerin secretion by neuroblastoma cells. Both cytokines have been previously found to regulate CMKLR1 and chemerin expression in human endothelial cells, keratinocytes (IL-1 $\beta$ ), and other cell types [37, 55]. Additionally, we observed that chemerin stimulated MMP-2 synthesis in a dosedependent manner. MMP-2 is a member of the matrix metalloproteinase family with important functions in tumorigenesis. Through processing of extracellular matrix and non-matrix proteins, MMP-2, and other members of the MMP family, contribute to cell invasion, metastasis and neovascularization [56]. Increased MMP-2 expression in neuroblastoma has been associated with increased angiogenesis, advanced stage, and poor clinical outcome $[57,58]$. Our results indicate that chemerin may contribute to an increased MMP-2 synthesis in neuroblastoma.
A

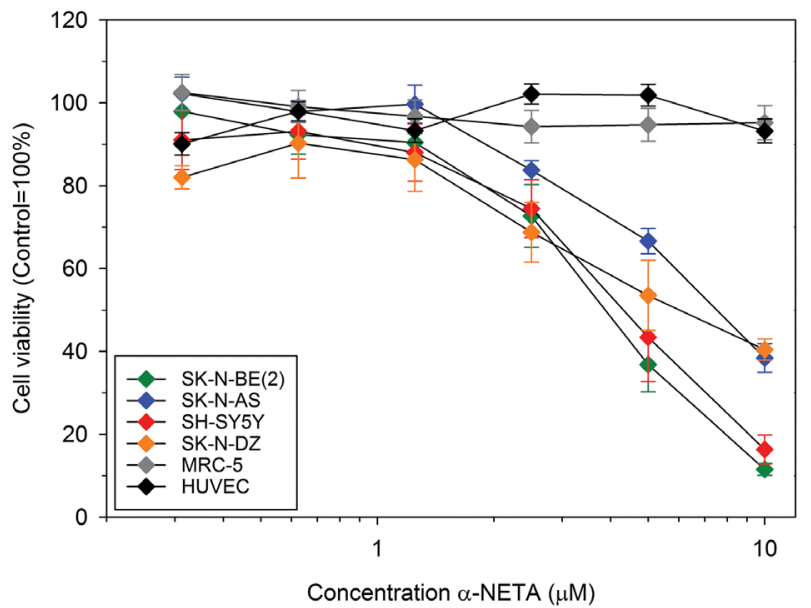

B

\begin{tabular}{|c|c|}
\hline Cell line & IC $_{50}$ with 95\% confidence interval \\
\hline SK-N-BE(2) & $3.87 \mu \mathrm{M}(3.45-4.34)$ \\
\hline SK-N-AS & $7.49 \mu \mathrm{M}(6.64-8.60)$ \\
\hline SK-N-DZ & $6.50 \mu \mathrm{M}(4.71-10.5)$ \\
\hline SH-SY5Y & $4.26 \mu \mathrm{M}(3.54-5.14)$ \\
\hline HUVEC & $>10 \mu \mathrm{M}$ \\
\hline MRC-5 & $>10 \mu \mathrm{M}$ \\
\hline
\end{tabular}

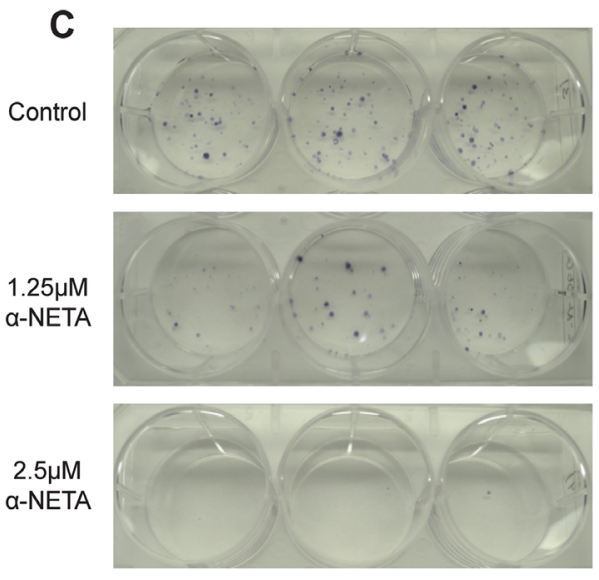

D

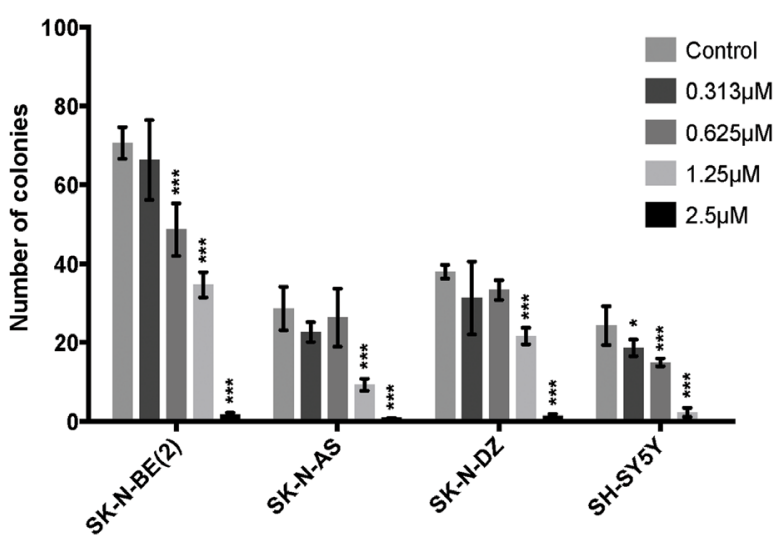

Figure 6: The CMKLR1 antagonist $\alpha$-NETA reduces the cell viability and clonogenicity of neuroblastoma cell lines. Cell viability was determined after $72 \mathrm{~h}$ of incubation with $\alpha$-NETA $(0.313-10 \mu \mathrm{M})$. A dose-dependent decrease in cell viability was observed in the neuroblastoma cell lines but not in MRC-5 and HUVEC cells (A). Data is presented as mean \pm SEM from three experiments. The $\mathrm{IC}_{50}$ values are given with $95 \%$ confidence intervals in (B). The mean of $\log \mathrm{IC}_{50} \mathrm{~s}$ in neuroblastoma cell lines was significantly lower than the hypothetical $\log \mathrm{IC}_{50}$ of the investigated normal cell lines (one sample t-test, $\mathrm{p}=0.029$; means: 0.726 vs 1). The CMKLR1 antagonist $\alpha$-NETA reduces the clonogenicity of SK-N-BE(2) cells $(\mathbf{C} ; 1.25$ and $2.5 \mu \mathrm{M}, \mathrm{n}=3)$ and other neuroblastoma cell lines $(\mathbf{D} ; 0.313-2.5 \mu \mathrm{M}$, $\mathrm{n}=3$ ) in a dose-dependent manner after $72 \mathrm{~h}$ treatment. Data is presented as mean $\pm \mathrm{SD}$ from a representative experiment. The experiment was repeated twice more with similar results. Statistical testing was performed using a two-way ANOVA $\mathrm{P}<0.001$ for both stimulation and between cell lines followed by Dunnett's post-test control vs. treatment ${ }^{*} \mathrm{P}<0.05,{ }^{* * *} \mathrm{P}<0.001$. 
In our work, we observed that $\alpha$-NETA, a small molecule inhibitor for CMKLR1, reduced the cell viability and clonogenicity of neuroblastoma cell lines. Initially identified as a choline acetyltransferase inhibitor, $\alpha$-NETA was recently found to be a more potent inhibitor of CMKLR1 [42]. In an in vivo xenograft study, we observed that continuous, long-term treatment with $\alpha$-NETA resulted in impaired tumor growth. However, no effect was observed when $\alpha$-NETA injections were initiated after the tumor had reached a volume of $0.15 \mathrm{ml}$. These results indicate that CMKLR1 function might be of greater importance during the early stages of tumor growth as well as tumor recurrence and relapse in neuroblastoma patients. However, SK-N-AS xenograft tumors grow very fast once the tumor has been established therefore providing only a narrow treatment window. In order to achieve a significant effect, a longer treatment window as given in the pretreatment group might be necessary. The results from the in vitro studies indicate a role of CMKLR1 during clone formation. Inhibiting CMKLR1 at a stage where the tumor has reached a certain size might therefore have a smaller impact. Since $\alpha$-NETA has only recently been described as a CMKLR1 inhibitor, potential off-target effects are not fully studied. Concerning bioavailability and stability of $\alpha$-NETA in vivo only limited data is available, hampering dose estimation. Hence, the concentration used in this study might have been too low to sufficiently abrogate CMKLR1 function in established tumors. Further studies are therefore necessary to determine the appropriate concentrations for $\alpha$-NETA in vivo. Additionally, the results should be confirmed using CMKLRl knockout neuroblastoma cell lines. Although we made several attempts to knock down/out CMKLR1 in neuroblastoma cell lines using both shRNA and the CRISPR/Cas9 system, we have established to date only one SK-N-AS cell line with a marked CMKLR1 downregulation (Supplementary Figure 7). Since this cell line grows very slowly and is unable to form distinct colonies in clonogenicity assays we have been unable to utilize it in functional in vitro or in vivo studies. While these findings, taken together with the results from the inhibitor studies, indicate that CMKLR1 may contribute to colony formation and tumorigenesis we have been unable to confirm these findings with additional knock down clones.

GPR1 is an additional active chemerin receptor expressed in the central nervous system, skeletal muscle, and adipose tissue [47]. In this work, we also demonstrate the expression of GPR1 mRNA and protein in neuroblastoma cell lines and primary tumor tissue. While most of the known chemerin functions have been connected to CMKLR1-mediated signaling, we cannot exclude that chemerin mediated signaling in neuroblastoma cell lines is not at least partly mediated by GPR1. However, GPR1 mediated calcium mobilization and ERK1/2 phosphorylation has been demonstrated to be much weaker compared to CMKLR1 [38, 39]. Recently, chemerin was found to activate RhoA/Rock signaling through CMKLR1 and GPR1 [40]. The Rho/ Rock pathway is involved in actin rearrangement, hence suggesting a potential role of the chemerin/CMKLR1/ GPR1 axis in migration and metastasis.

CCRL2, the third known chemerin receptor is present on myeloid cells, mast cells and CD34+ bone marrow precursors [47]. While not actively signaling, it was found

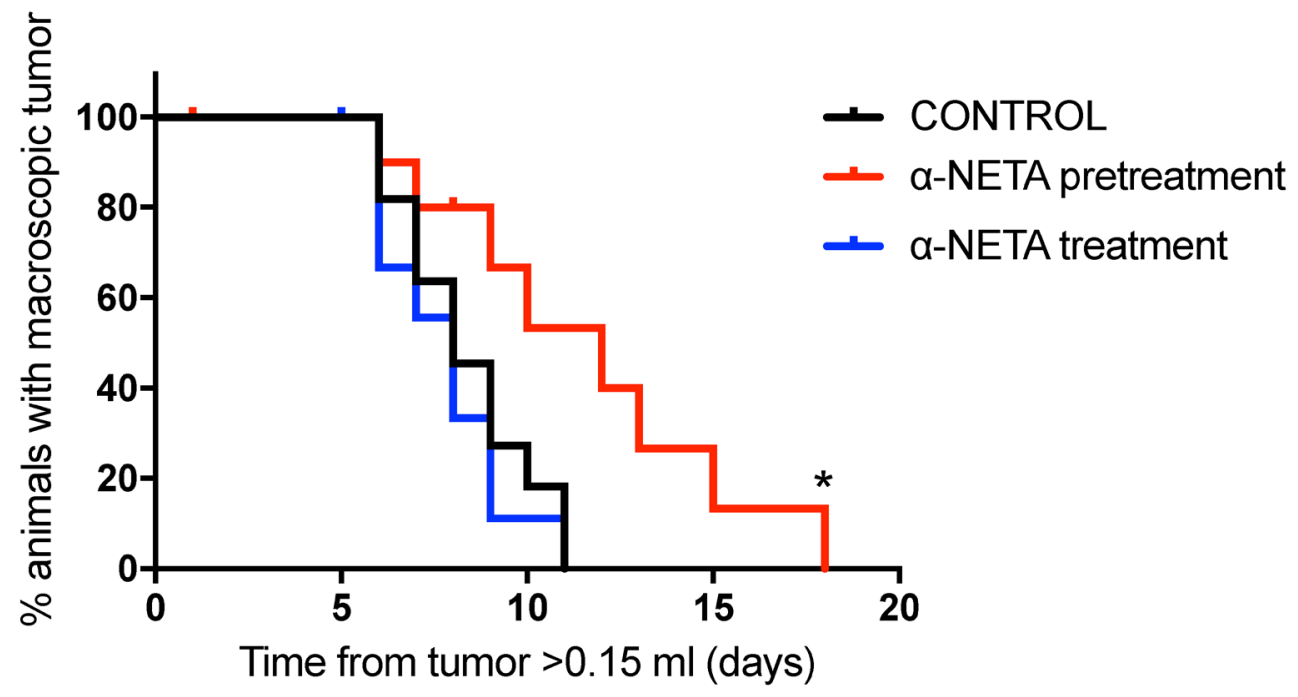

Figure 7: Early and prolonged CMKLR1 inhibition with $\alpha$-NETA impairs tumor growth in vivo. Kaplan-Meier survival plots of nude mice ( $\mathrm{n}=11$ in control group and in pre-treatment group, $\mathrm{n}=10$ in treatment group) injected daily s.c. with $20 \mathrm{mg} / \mathrm{kg} \alpha-\mathrm{NETA}$ after the tumor reached $0.15 \mathrm{ml}$ (treatment group), $10 \mathrm{mg} / \mathrm{kg} \alpha$-NETA from the day after tumor cell injection and $20 \mathrm{mg} / \mathrm{kg}$ when the tumor reached $0.15 \mathrm{ml}$ (pre-treatment group) or $10 \% \mathrm{Captisol}^{\circledR}$ (control group). Survival, defined as time needed for the animals to grow a macroscopic tumor (volume $>1.5 \mathrm{ml}$ ), was significantly prolonged in the pre-treatment group $(\log$ rank test $\mathrm{P}=0.015$, control vs. pretreatment $\mathrm{P}=0.019$ and control vs. treatment $\mathrm{P}=0.51$ ). 
Table 1: Antibodies used in the study

\begin{tabular}{|c|c|c|}
\hline Antibody & Application & Source \\
\hline Anti-ChemR23 & WB, IHC & \#STJ92262, St John’s Laboratory \\
\hline Anti-Human ChemR23 & IF-P, ICC & \#MAB362, R\&D Systems \\
\hline Anti-GPCR GPR1 & WB & \#ab157209, abcam \\
\hline Anti-GPCR GPR1 & ICC & \#ab121315, abcam \\
\hline Anti-GPCR GPR1 & IHC & \#ab188977, abcam \\
\hline Anti-TIG2 Antibody (K-15) & WB, IF-P & \#sc-47482, Santa Cruz Biotechnology \\
\hline Anti-Human Chemerin & IHC & \#MAB2324, R\&D Systems \\
\hline Anti-beta Actin & WB & \#ab8227, abcam \\
\hline Anti-p44/42 MAPK (Erk1/2) & WB & \#4695, Cell Signaling Technology \\
\hline Anti-Phospho-p44/42 MAPK (Erk1/2) (Thr202/Tyr204) & WB & \#4370, Cell Signaling Technology \\
\hline Anti-Akt & WB & \#9272, Cell Signaling Technology \\
\hline Anti-Phospho-Akt (Ser473) (D9E) & WB & \#4060, Cell Signaling Technology \\
\hline Anti-Phospho-MEK1/2 (Ser217/221) & WB & \#9121, Cell Signaling Technology \\
\hline Goat Anti-Rabbit IgG H\&L (HRP) & WB & \#ab6721, abcam \\
\hline Swine Anti-Goat Ig's, HRP & WB & \#ACI0404, Thermo Fisher Scientific \\
\hline Goat anti-Rabbit IgG $(\mathrm{H}+\mathrm{L})$, Alexa Fluor 488 & ICC & \# A-11008, Thermo Fisher Scientific \\
\hline Donkey anti-Goat IgG $(\mathrm{H}+\mathrm{L})$, Alexa Fluor 594 & IF-P & \#A-11058, Thermo Fisher Scientific \\
\hline Rabbit anti-Mouse IgG $(\mathrm{H}+\mathrm{L})$, Alexa Fluor 488 & IF-P & \# A-11059, Thermo Fisher Scientific \\
\hline
\end{tabular}

to increase local chemerin levels suggesting that CCRL2 presents chemerin to CMKLR1 or GPR1 on neighboring cells [33]. Akram et al. recently identified a role of CCRL2 in colorectal cancer liver metastases [35]. Although we were able to detect CCRL2 mRNA in neuroblastoma cell lines (data not shown), the role of CCRL2 in neuroblastoma was not addressed in the present study.

Our results demonstrate, for the first time, the presence of a fully active and functional chemerin/ CMKLR1 axis in childhood neuroblastoma. Neuroblastoma cells produce chemerin that can promote survival in an autocrine manner. Inhibition of the chemerin/CMKLR1 axis impaired neuroblastoma cell growth in vitro and in vivo. Our findings provide new insight into the pathobiology of neuroblastoma. Pharmacological interventions targeting the chemerin/CMKLR1 signaling pathway may be an important adjuvant therapy for children with neuroblastoma, but further preclinical in vivo studies are warranted.

\section{MATERIALS AND METHODS}

\section{Microarray gene expression analysis}

Gene expression analysis was performed using the publicly available R2: Genomics Analysis and Visualization Platform (http://r2.amc.nl).

\section{Antibodies and reagents}

The antibodies used in this study are listed in Table 1. Recombinant human IL-1 $\beta$ was purchased from Cell Guidance Systems Ltd. (Cambridge, UK). Recombinant human TNF $\alpha$ and chemerin were obtained from R\&D Systems, Inc. (Minneapolis, USA) and $\alpha$-NETA was from Santa Cruz Biotechnology, Inc. (Dallas, USA).

\section{Cell lines and human tissue samples}

The human neuroblastoma cell lines SK-NAS, SK-N-SH, SK-N-DZ, SK-N-FI, SH-EP1, Kelly, SH-SY5Y, and IMR-32 as well as the hepatocellular carcinoma cell line HepG2 were purchased from the ATCC (American Type Culture Collection), and SKN-BE(2) cells were bought from DSMZ (Deutsche Sammlung von Mikroorganismen und Zellkulturen). The cells were cultivated in RPMI-1640 medium containing L-glutamine and sodium bicarbonate (Sigma-Aldrich Norway AS, Oslo, Norway) supplemented with $10 \%$ heat-inactivated FBS (Thermo Fisher Scientific Inc.) at $37^{\circ} \mathrm{C}$ in humidified air with $5 \% \mathrm{CO}_{2}$. The human fibroblast cell line MRC-5 and human umbilical vein endothelial cells (HUVEC) were purchased from the ATCC and cultivated in EGM-2 BulletKit with 2\% FBS (Lonza, Basel, Switzerland) 
and MEM supplemented with 2mM L-glutamine, $1 \%$ non-essential amino acids and 10\% FBS, respectively. Mycoplasma tests were regularly performed using the MycoAlert ${ }^{\mathrm{TM}}$ PLUS Mycoplasma Detection Kit (Lonza, Basel, Switzerland).

Neuroblastoma tumor tissue was obtained from the Karolinska University Hospital according to the ethical approval from the Stockholm Regional Ethical Review Board and the Karolinska University Hospital Research Ethics Committee (approval ID 2009/1369$31 / 1$ and 03-736). Informed consent (written or verbal) was provided by the parents or guardians for the use of tumor samples in research. Samples were collected during surgery, snap-frozen in liquid nitrogen and stored at $-80^{\circ} \mathrm{C}$ until further use. Twenty-seven neuroblastoma samples derived from children of different ages and all clinical stages, including different biological subsets [36] were analyzed.

\section{RNA isolation and reverse transcriptase PCR}

Total RNA was isolated using the RNeasy ${ }^{\circledR}$ Mini Kit (Qiagen Norge, Oslo, Norway) according to the provided manual. The RNA quantity and quality was determined using the NanoDrop 1000 (Thermo Fisher Scientific Inc.). One $\mu \mathrm{g}$ RNA was used for cDNA synthesis with the iScript ${ }^{\mathrm{TM}}$ cDNA Synthesis Kit (Bio-Rad Laboratories $\mathrm{AB}$, Oslo, Norway). PCR was performed in a $25 \mu \mathrm{l}$ reaction mix containing $2 \mu \mathrm{l}$ cDNA, $12.5 \mu \mathrm{l}$ AccuStart ${ }^{\mathrm{TM}}$ II GelTrack PCR SuperMix (Quanta Biosciences, Gaithersburg, USA), $400 \mathrm{nM}$ of each primer and $10.1 \mu \mathrm{l}$ of ultra-pure $\mathrm{H}_{2} \mathrm{O}$ (Biochrom $\mathrm{GmbH}$, Berlin, Germany). The PCR run was performed in a T100 TM Thermal Cycler (Bio-Rad Laboratories AB, Oslo, Norway) as follows: $2 \mathrm{~min}$ at $94^{\circ} \mathrm{C}$ and 35 cycles of $94^{\circ} \mathrm{C}$ for $20 \mathrm{~s}$, $62^{\circ} \mathrm{C}$ for $30 \mathrm{~s}$ and $72^{\circ} \mathrm{C}$ for $90 \mathrm{~s}$. The sequences for the PCR primers were the following: APRT (housekeeping) 5'-CCCGAGGCTTCCTCTTTGGC-3' (sense) and 5'-CTCCCTGCCCTTAAGCGAGG-3' (antisense) [59], CMKLR1 5'-GCCAACCTGCATGGGAAAATA-3' (sense) and 5'-GTGAGGTAGCAAGCTGTGATG-3' (antisense), GPR1 5'-CAATCTAGCCATTGCGG ATTTCA-3' (sense) and 5'-CCGATGAGATA AGACAGGATGGA-3' (antisense), chemerin 5'-AGAAACCCGAGTG CAAAGTCA-3' (sense) and 5'-AGAACTTGGGTCTCTATGGGG-3' (antisense) (Primer bank ID 215272316c3, 148228828c3 and $218931208 \mathrm{c} 1$ http://pga.mgh.harvard.edu/primerbank/ index.html).

PCR products were analyzed by gel electrophoresis. The $1.8 \%$ SeaKem $^{\circledR}$ LE Agarose gel (Lonza) was stained with GelRed ${ }^{\mathrm{TM}}$ (Biotium, Inc., Hayward, USA) and visualized under UV light in the BioDoc-It ${ }^{\mathrm{TM}}$ Imaging System (UVP, LLC, Upland, USA). The PCR results for CMKLR1, GPR1 and chemerin were confirmed with a second, independent primer set (data not shown).

\section{Western blot}

Cultured cells were washed briefly with phosphatebuffered saline (PBS, Biochrom $\mathrm{GmbH}$ ) and harvested in RIPA Lysis and Extraction Buffer containing Halt ${ }^{\mathrm{TM}}$ Protease and Phosphatase Inhibitor Cocktail (Thermo Fisher Scientific Inc.). Following sonication, the protein concentration was determined using a Protein Quantification Assay (MACHEREY-NAGEL GmbH \& Co. KG, Düren, Germany). The protein lysates were supplemented with NuPAGE ${ }^{\circledR}$ LDS Sample Buffer (4X) (Thermo Fisher Scientific Inc.) as well as 100mM DTT (Sigma-Aldrich Norway AS) and incubated for $10 \mathrm{~min}$ at $70^{\circ} \mathrm{C}$. Equal amounts of protein were separated on NuPAGETM Novex ${ }^{\text {TM }}$ 4-12\% Bis-Tris Protein Gels (Thermo Fisher Scientific Inc.) and transferred onto a $0.45 \mu \mathrm{m}$ PVDF Membrane (Merck Life Science AS, Oslo, Norway) according to the XCell SureLock Mini-Cell technical guide (Thermo Fisher Scientific Inc.). The membranes were blocked in TBS-T (Tris-buffered saline (TBS) with $0.1 \%$ Tween-20; Sigma-Aldrich Norway AS) containing 5\% $(\mathrm{w} / \mathrm{v})$ skimmed milk powder. Incubation with the primary antibody was performed overnight at $4^{\circ} \mathrm{C}$ according to antibody supplier recommendation in either blocking buffer or 5\% BSA (AppliChem, Darmstadt, Germany) in TBS-T. Following three washes in TBS-T, the membranes were incubated in the appropriate secondary antibody solution for $1 \mathrm{~h}$ at room temperature. After four washes, detection and visualization were performed using SuperSignal ${ }^{\text {TM }}$ West Pico Chemiluminescent Substrate (Thermo Fisher Scientific Inc.) and the ImageQuant LAS 4000 imager (GE Healthcare, Oslo, Norway). MagicMark ${ }^{\mathrm{TM}}$ XP Western Protein Standard (Thermo Fisher Scientific Inc.) was used to estimate the molecular mass of the detected proteins. Densitometry was performed using Fiji software [60].

\section{ICC}

For immunocytochemistry, cells were grown on 8-well $\mu$-Slide (ibidi GmbH, Munich, Germany) for 24h. Cells were then rinsed briefly with PBS and fixed with $4 \%$ formaldehyde for $20 \mathrm{~min}$. After three washes with PBS, unspecific binding sites were blocked with $1 \%$ BSA in PBS containing 0.3\% Triton-X-100 (SigmaAldrich Norway AS) for $45 \mathrm{~min}$. The cells were incubated with primary antibodies diluted in blocking solution at $4^{\circ} \mathrm{C}$ overnight. After three washes with PBS, the cells were incubated with the secondary antibodies diluted in blocking solution for $1 \mathrm{~h}$ at room temperature, protected from light. Following three washes with PBS, the nuclei were stained with Hoechst 33342 (ImmunoChemistry Technologies, LLC, Bloomington, USA) for $10 \mathrm{~min}$. The cells were washed $2 \mathrm{x}$ with PBS and covered with Mounting Medium for fluorescence microscopy (ibidi $\mathrm{GmbH}$ ). The cells were subsequently examined with a Leica TCS SP5 or Zeiss LSM780 confocal microscope. 


\section{IHC}

Formalin-fixed and paraffin-embedded tissue sections were deparaffinized in xylene and graded alcohols, hydrated and washed in PBS. After antigen retrieval in a sodium citrate buffer ( $\mathrm{pH} 6$ ) in a microwave oven, the endogenous peroxidase was blocked by $0.3 \%$ $\mathrm{H}_{2} \mathrm{O}_{2}$ for $15 \mathrm{~min}$. Sections were incubated overnight at $4^{\circ} \mathrm{C}$ with the primary antibody. As a secondary antibody, the anti-rabbit-HRP SuperPicTure Polymer detection kit (879663, Zymed-Invitrogen, San Francisco, USA) or antimouse EnVision-HRP (Dako, Agilent Technologies, Inc., Santa Clara, USA) was used. A matched isotype control was used as a control for nonspecific background staining.

For immunofluorescence histology studies (IF-P), the sections were treated as described above and stained sequentially with the primary and secondary antibody sets. Alexa Fluor ${ }^{\circledR} 488$ and Alexa Fluor ${ }^{\circledR} 594$ conjugated secondary antibodies were used to visualize positive staining.

The fluorescence labeled tissue sections were examined using the Zeiss LSM780 confocal microscope and the immunoperoxidase stained sections using the Leica DMI6000B microscope.

\section{Calcium mobilization assay}

SK-N-SH cells were seeded into an 8-well $\mu$-Slide (ibidi $\mathrm{GmbH}$ ) and incubated overnight in RPMI containing $10 \%$ FBS. The following day the cells were washed and preloaded with $20 \mu \mathrm{M}$ Cal-520 (AATBio, Sunnyvale, USA) in Hanks' Buffer with 20mM Hepes (HHBS) with $0.04 \%$ Pluronic ${ }^{\circledR}$ F-127 (AATBio). After 90min of incubation at $37^{\circ} \mathrm{C}$, the dye solution was replaced with HHBS and the cells were subsequently examined with a Leica TCS SP5 confocal microscope in the presence or absence $2 \mathrm{mM}$ EDTA. Before the addition of $10 \mathrm{nM}$ of chemerin, a baseline measurement was taken. Images were then obtained and analyzed using the Leica LAS AF software.

\section{Stimulation of cells with chemerin}

Cells were seeded in $35 \mathrm{~mm}$ cell culture dishes (Corning, Corning, USA) and incubated overnight in complete growth medium. The cells were serum starved for $24 \mathrm{~h}$ prior to stimulation with recombinant human chemerin (0.1-10 nM) for 5, 10, 20 and 30min.

\section{Chemerin ELISA}

SK-N-AS cells were seeded in 96-well culture plates. The following day, the medium was removed and the cells were serum starved $(0.1 \%$ FBS $)$ overnight. The cells were then stimulated with either $10 \%$ FBS or $10 \mathrm{ng} / \mathrm{ml}, 50 \mathrm{ng} / \mathrm{ml} \mathrm{TNF} \alpha$, or IL- $1 \beta$ in serum reduced medium $(0.1 \% \mathrm{FBS})$ for 12 and $24 \mathrm{~h}$. After incubation, supernatants from 10 parallels were pooled and spun for $5 \mathrm{~min}$ at $200 \mathrm{xg}$ to pellet floating cells. The cell supernatant was concentrated 10x using Amicon Ultra- 0.5 Centrifugal Filter Unit (Merck Life Science AS). The chemerin quantity was assayed by ELISA according to the manufacturer's instructions (Human Chemerin Quantikine ELISA, R\&D Systems, Inc).

\section{Real-time zymography}

SK-N-AS and SK-N-BE(2) cells were seeded in 96-well plates (Corning, Corning, USA) and left to attach overnight. The medium was replaced with OptiMEM and the cells were serum-starved for $24 \mathrm{~h}$. The cells were thereafter exposed to chemerin $(0.1-100 \mathrm{nM})$ for 6 , 12, 24 and 48h, using Opti-MEM serum-free medium. $\mathrm{TNF} \alpha(10 \mathrm{ng} / \mathrm{ml})$ was used as a positive control. After the incubation, the medium from three independent samples was pooled, centrifuged at $200 \mathrm{xg}$ for $5 \mathrm{~min}$ at $4^{\circ} \mathrm{C}$, and made 10 and $100 \mathrm{mM}$ with respect to $\mathrm{CaCl}_{2}$ and Hepes ( $\mathrm{pH}$ 7.5). Undiluted samples were analyzed for the expression of gelatin degrading enzymes using real-time zymography. Zymography was performed as described previously [61] with the exception that $0.1 \%$ $(\mathrm{w} / \mathrm{v})$ 2-methoxy-2,4-diphenyl-3(2H)-furanone (MDPF)fluorescent labeled gelatin was incorporated in the $7.5 \%$ SDS-PAGE separating gel instead of $0.1 \%(\mathrm{w} / \mathrm{v})$ unlabeled gelatin. Gelatin (Sigma-Aldrich Norway AS) was labeled with the fluorescent dye 2-methoxy-2,4-diphenyl-3(2H)furanone (Sigma-Aldrich Norway AS) to give MDPFgelatin as described previously [62]. The main difference between normal gelatin zymography and real-time gelatin zymography is that in real-time zymography the gel is not stained and hence it is possible to follow the degradation of the gelatin in real time without staining. In the present work, each gel was monitored continuously and a picture of the gel was taken approximately every second hour for fifteen hours or more. Gelatinase activity was evident as dark bands against the un-degraded fluorescent background.

\section{Cell viability assay}

A colorimetric 3-(4,5-dimethylthiazol-2-yl)-2,5diphenyltetrazolium bromide (MTT) viability assay [63] was employed to assess the effect of $\alpha$-NETA on the viability of neuroblastoma cell lines as well as MRC-5 and HUVEC. The cells were seeded in 96-well plates in full growth media. After $24 \mathrm{~h}$ the cells were washed once with Opti-MEM (Thermo Fisher Scientific Inc.) before being incubated with $313 \mathrm{nM}-10 \mu \mathrm{M} \alpha$-NETA (dissolved in dimethylsulfoxide, DMSO) in Opti-MEM for $72 \mathrm{~h}$. Control cells received DMSO corresponding to the highest concentration present in the $\alpha$-NETA treated cells. The MTT solution $(20 \mu \mathrm{l}$ of $5 \mathrm{mg}$ MTT, Sigma-Aldrich Norway AS, per $\mathrm{ml}$ phosphate buffered saline) was added to each well. After 2 -3h additional incubation $150 \mu$ l of solution were 
carefully removed from each well and $100 \mu$ isopropanol containing $0.04 \mathrm{M} \mathrm{HCl}$ were added and mixed thoroughly. To further facilitate formazan crystal solubilizing, the plates were placed on an orbital shaker for $1 \mathrm{~h}$ at room temperature. The absorbance was measured with a CLARIOstar plate reader (BMG LABTECH, Ortenberg, Germany) at $590 \mathrm{~nm}$. The experiment was repeated three times with at least three parallels per treatment and the cell viability was calculated as the ratio of the mean OD of treated cells over vehicle treated control cells ( $100 \%$ living cells). The $\mathrm{IC}_{50} \mathrm{~s}$ were calculated from log concentration curves using non-linear regression analysis in GraphPad Prism.

\section{Clonogenic assay}

SK-N-AS, SK-N-BE(2), SK-N-DZ, and SH-SY5Y cells were seeded in 6 well plates and allowed to attach to the surface overnight. The cells were washed and the medium was replaced with Opti-MEM containing 313 $\mathrm{nM}-5 \mu \mathrm{M} \alpha$-NETA dissolved in DMSO. The control cells received DMSO corresponding to the highest concentration present in the $\alpha$-NETA treated cells. After $72 \mathrm{~h}$ the medium was replaced with regular growth medium containing $10 \%$ FBS. When the cell colonies reached $\geq 50$ cells, the plates were briefly rinsed with PBS (Thermo Fisher Scientific Inc.), fixed in 4\% formaldehyde (Merck Life Science AS), and stained with Giemsa (Merck Life Science AS). Colonies containing at least 50 cells were counted.

\section{In vivo xenograft study}

All animal experiments were approved by the local ethical committee (approval ID: N231/14) appointed by the Swedish Board of Agriculture and conducted in accordance with the local guidelines and the European Directive 2010/63/EU.

Female, immunodeficient nude mice (NMRI-nu/nu, Taconic) were used for the xenograft studies. The animals were housed in cages containing 2-6 mice with ad libitum access to food and sterile water. The cages contained environmental enrichment (a house, nest material and gnawing sticks) and the mice were kept on a $12 \mathrm{~h}$ day/ night cycle.

Each mouse was anaesthetized (Isoflurane $4 \%$ induction and 2\% maintenance) and injected subcutaneously (s.c.) on the right flank with $1 \times 10^{7}$ SK-NAS cells. After $24 \mathrm{~h}, 11$ animals were randomly selected for the pre-treatment group and received $10 \mathrm{mg} / \mathrm{kg} \alpha$-NETA s.c. daily. $\alpha$-NETA was dissolved in $10 \%$ Captisol $^{\circledR}$ (Ligand Pharmaceuticals, Inc., La Jolla, USA). The mice were weighed and tumors were measured every other day. The tumor volume was calculated with the following formula: length $\times(\text { width })^{2} \times 0.44$. When tumors reached a volume of $\geq 0.15 \mathrm{ml}$ the mice were randomized to either treatment group $(20 \mathrm{mg} / \mathrm{kg} \alpha-\mathrm{NETA}$, daily s.c. injections, $\mathrm{n}=11$ in pre-treatment group and $\mathrm{n}=10$ in treatment group) or control group (vehicle, daily s.c. injections, $\mathrm{n}=11$ ).
When the tumors from the pre-treatment group were $\geq$ $0.15 \mathrm{ml}$ the $\alpha$-NETA dose was increased to $20 \mathrm{mg} / \mathrm{kg}$.

The mice were closely monitored for weight loss and other signs of toxicity. In accordance with the ethical guidelines the animals were sacrificed when tumors reached a volume of $2 \mathrm{ml}$, or a diameter over $2 \mathrm{~cm}$, and the tumors were resected. Hence, survival was defined as time needed for the animals to grow a macroscopic tumor (volume $>1.5 \mathrm{ml}$ ). Smaller parts of the tumors were fixed in formaldehyde or frozen.

Tumor volume growth was analyzed using ratebased comparison. By fitting each tumor's growth curve to an exponential model (by correlating the logarithm of the tumor volume measurements to the time), the slope, as an estimate for the tumor growth, for each tumor's growth could be determined [64].

\section{Statistics}

SigmaPlot and GraphPad Prism software was used for the statistical analysis and the graphs. Differences between several groups were assessed with one-way ANOVA and Bonferroni post-test or two-way ANOVA and Dunnett's post-test. One sample t-test was used to compare differences between one group and a hypothetical mean. The survival analysis on tumor growth in vivo was performed using the Kaplan-Meier method and statistical differences between groups were performed using logrank test.

\section{Abbreviations}

CCRL2, C-C chemokine receptor-like 2; CMKLR1, chemokine-like receptor 1; GPR1, G-protein-coupled receptor 1 ; TME, tumor microenvironment; $\alpha$-NETA, 2-( $\alpha$-naphthoyl) ethyltrimethylammonium iodide; MMP, matrix metalloproteases; ICC, Immunocytochemistry; IHC, immunohistochemistry; IF-P, immunofluorescence on paraffin-embedded samples.

\section{Author contributions}

Conception and design: C.T., B.S., U.M., I.S., M.W., J.I.J., J.O.W., L.L., P.K. Acquisition of data: C.T., I.S., B.S., M.W., L.L., L.H.M.E., J.O.W., Analysis and interpretation of data: C.T., B.S., U.M., I.S., M.W., J.I.J., J.O.W., L.L., L.H.M.E., P.K., Writing and review of manuscript: C.T., B.S., U.M., I.S., M.W., J.I.J., J.O.W., L.L., L.H.M.E., P.K.

\section{ACKNOWLEDGMENTS}

We thank Eli Berg for her excellent support with the Zymography experiments and Joe Hurley for proofreading. 


\section{CONFLICTS OF INTEREST}

The authors declare no conflicts of interest.

\section{FUNDING}

This study was funded with grants from the University of Tromsø, Northern Regional Health Authority (SFP996-11), Erna and Olav Aakre Foundation for Cancer Research (A20310), Tromsø, Norway as well as The Swedish Children's Cancer Foundation, Swedish Foundation for Strategic Research http://nnbcr.se/, Swedish Cancer Society and Swedish Research Council.

\section{REFERENCES}

1. Park JR, Bagatell R, London WB, Maris JM, Cohn SL, Mattay KK, Hogarty M; COG Neuroblastoma Committee. Children's Oncology Group's 2013 blueprint for research: neuroblastoma. Pediatr Blood Cancer. 2013; 60: 985-93. http://doi.org/10.1002/pbc.24433.

2. Matthay KK, Maris JM, Schleiermacher G, Nakagawara A, Mackall CL, Diller L, Weiss WA. Neuroblastoma. Nat Rev Dis Primers. 2016; 2: 16078. http://doi.org/10.1038/ nrdp.2016.78.

3. Hanahan D, Weinberg RA. Hallmarks of cancer: the next generation. Cell. 2011; 144: 646-74. http://doi. org/10.1016/j.cell.2011.02.013.

4. Mantovani A, Allavena P, Sica A, Balkwill F. Cancerrelated inflammation. Nature. 2008; 454: 436-44. http://doi. org/10.1038/nature07205.

5. Larsson K, Kock A, Idborg H, Arsenian Henriksson M, Martinsson T, Johnsen JI, Korotkova M, Kogner P, Jakobsson PJ. COX/mPGES-1/PGE2 pathway depicts an inflammatory-dependent high-risk neuroblastoma subset. Proc Natl Acad Sci U S A. 2015; 112: 8070-5. http://doi. org/10.1073/pnas.1424355112.

6. Borriello L, Seeger RC, Asgharzadeh S, DeClerck YA. More than the genes, the tumor microenvironment in neuroblastoma. Cancer Lett. 2015. http://doi.org/10.1016/j. canlet.2015.11.017.

7. Asgharzadeh S, Salo JA, Ji L, Oberthuer A, Fischer M, Berthold F, Hadjidaniel M, Liu CW, Metelitsa LS, PiqueRegi R, Wakamatsu P, Villablanca JG, Kreissman SG, et al. Clinical significance of tumor-associated inflammatory cells in metastatic neuroblastoma. J Clin Oncol. 2012; 30: 3525-32. http://doi.org/10.1200/JCO.2011.40.9169.

8. Carlson LM, Rasmuson A, Idborg H, Segerstrom L, Jakobsson PJ, Sveinbjornsson B, Kogner P. Low-dose aspirin delays an inflammatory tumor progression in vivo in a transgenic mouse model of neuroblastoma. Carcinogenesis. 2013; 34: 1081-8. http://doi.org/10.1093/ carcin/bgt009.
9. Johnsen JI, Lindskog M, Ponthan F, Pettersen I, Elfman L, Orrego A, Sveinbjornsson B, Kogner P. NSAIDs in neuroblastoma therapy. Cancer Lett. 2005; 228: 195-201. http://doi.org/10.1016/j.canlet.2005.01.058.

10. Goralski KB, McCarthy TC, Hanniman EA, Zabel BA, Butcher EC, Parlee SD, Muruganandan S, Sinal CJ. Chemerin, a novel adipokine that regulates adipogenesis and adipocyte metabolism. J Biol Chem. 2007; 282: 28175 88. http://doi.org/10.1074/jbc.M700793200.

11. Landgraf K, Friebe D, Ullrich T, Kratzsch J, Dittrich K, Herberth G, Adams V, Kiess W, Erbs S, Korner A. Chemerin as a mediator between obesity and vascular inflammation in children. J Clin Endocrinol Metab. 2012; 97: E556-64. http://doi.org/10.1210/jc.2011-2937.

12. Kulig P, Kantyka T, Zabel BA, Banas M, Chyra A, Stefanska A, Tu H, Allen SJ, Handel TM, Kozik A, Potempa J, Butcher EC, Cichy J. Regulation of chemerin chemoattractant and antibacterial activity by human cysteine cathepsins. J Immunol. 2011; 187: 1403-10. http:// doi.org/10.4049/jimmunol.1002352.

13. Schultz S, Saalbach A, Heiker JT, Meier R, Zellmann T, Simon JC, Beck-Sickinger AG. Proteolytic activation of prochemerin by kallikrein 7 breaks an ionic linkage and results in C-terminal rearrangement. Biochem J. 2013; 452: 271-80. http://doi.org/10.1042/BJ20121880.

14. Berg V, Sveinbjornsson B, Bendiksen S, Brox J, Meknas K, Figenschau Y. Human articular chondrocytes express ChemR23 and chemerin; ChemR23 promotes inflammatory signalling upon binding the ligand chemerin(21-157). Arthritis Res Ther. 2010; 12: R228. http://doi.org/10.1186/ ar3215.

15. Pachynski RK, Zabel BA, Kohrt HE, Tejeda NM, Monnier J, Swanson CD, Holzer AK, Gentles AJ, Sperinde GV, Edalati A, Hadeiba HA, Alizadeh AA, Butcher EC. The chemoattractant chemerin suppresses melanoma by recruiting natural killer cell antitumor defenses. J Exp Med. 2012; 209: 1427-35. http://doi.org/10.1084/jem.20112124.

16. Wang N, Wang QJ, Feng YY, Shang W, Cai M. Overexpression of chemerin was associated with tumor angiogenesis and poor clinical outcome in squamous cell carcinoma of the oral tongue. Clin Oral Investig. 2014; 18: 997-1004. http://doi.org/10.1007/s00784-013-1046-8.

17. Kumar JD, Holmberg C, Kandola S, Steele I, Hegyi P, Tiszlavicz L, Jenkins R, Beynon RJ, Peeney D, Giger OT, Alqahtani A, Wang TC, Charvat TT, et al. Increased expression of chemerin in squamous esophageal cancer myofibroblasts and role in recruitment of mesenchymal stromal cells. PLoS One. 2014; 9: e104877. http://doi. org/10.1371/journal.pone.0104877.

18. Wang C, Wu WK, Liu X, To KF, Chen GG, Yu J, Ng EK. Increased serum chemerin level promotes cellular invasiveness in gastric cancer: a clinical and experimental study. Peptides. 2014; 51: 131-8. http://doi.org/10.1016/j. peptides.2013.10.009. 
19. Lande R, Gafa V, Serafini B, Giacomini E, Visconti A, Remoli ME, Severa M, Parmentier M, Ristori G, Salvetti M, Aloisi F, Coccia EM. Plasmacytoid dendritic cells in multiple sclerosis: intracerebral recruitment and impaired maturation in response to interferon-beta. J Neuropathol Exp Neurol. 2008; 67: 388-401. http://doi.org/10.1097/ NEN.0b013e31816fc975.

20. Yamaguchi Y, Du XY, Zhao L, Morser J, Leung LL. Proteolytic cleavage of chemerin protein is necessary for activation to the active form, Chem157S, which functions as a signaling molecule in glioblastoma. J Biol Chem. 2011; 286: 39510-9. http://doi.org/10.1074/jbc.M111.258921.

21. Mattern A, Zellmann T, Beck-Sickinger AG. Processing, signaling, and physiological function of chemerin. IUBMB Life. 2014; 66: 19-26. http://doi.org/10.1002/iub.1242.

22. Zabel BA, Allen SJ, Kulig P, Allen JA, Cichy J, Handel TM, Butcher EC. Chemerin activation by serine proteases of the coagulation, fibrinolytic, and inflammatory cascades. J Biol Chem. 2005; 280: 34661-6. http://doi.org/10.1074/ jbc.M504868200.

23. Guillabert A, Wittamer V, Bondue B, Godot V, Imbault V, Parmentier M, Communi D. Role of neutrophil proteinase 3 and mast cell chymase in chemerin proteolytic regulation. J Leukoc Biol. 2008; 84: 1530-8. http://doi.org/10.1189/ jlb.0508322.

24. Wittamer V, Franssen JD, Vulcano M, Mirjolet JF, Le Poul E, Migeotte I, Brezillon S, Tyldesley R, Blanpain C, Detheux M, Mantovani A, Sozzani S, Vassart G, et al. Specific recruitment of antigen-presenting cells by chemerin, a novel processed ligand from human inflammatory fluids. J Exp Med. 2003; 198: 977-85. http:// doi.org/10.1084/jem.20030382.

25. Luangsay S, Wittamer V, Bondue B, De Henau O, Rouger L, Brait M, Franssen JD, de Nadai P, Huaux F, Parmentier M. Mouse ChemR23 is expressed in dendritic cell subsets and macrophages, and mediates an anti-inflammatory activity of chemerin in a lung disease model. J Immunol. 2009; 183: 6489-99. http://doi.org/10.4049/jimmunol.0901037.

26. Zabel BA, Ohyama T, Zuniga L, Kim JY, Johnston B, Allen SJ, Guido DG, Handel TM, Butcher EC. Chemokine-like receptor 1 expression by macrophages in vivo: regulation by TGF-beta and TLR ligands. Exp Hematol. 2006; 34: 110614. http://doi.org/10.1016/j.exphem.2006.03.011.

27. Parolini S, Santoro A, Marcenaro E, Luini W, Massardi L, Facchetti F, Communi D, Parmentier M, Majorana A, Sironi M, Tabellini G, Moretta A, Sozzani S. The role of chemerin in the colocalization of $\mathrm{NK}$ and dendritic cell subsets into inflamed tissues. Blood. 2007; 109: 3625-32. http://doi. org/10.1182/blood-2006-08-038844.

28. Zabel BA, Silverio AM, Butcher EC. Chemokine-like receptor 1 expression and chemerin-directed chemotaxis distinguish plasmacytoid from myeloid dendritic cells in human blood. J Immunol. 2005; 174: 244-51.

29. Sell H, Laurencikiene J, Taube A, Eckardt K, Cramer A, Horrighs A, Arner P, Eckel J. Chemerin is a novel adipocyte-derived factor inducing insulin resistance in primary human skeletal muscle cells. Diabetes. 2009; 58: 2731-40. http://doi.org/10.2337/db09-0277.

30. Imai K, Takai K, Hanai T, Shiraki M, Suzuki Y, Hayashi H, Naiki T, Nishigaki Y, Tomita E, Shimizu M, Moriwaki $\mathrm{H}$. Impact of serum chemerin levels on liver functional reserves and platelet counts in patients with hepatocellular carcinoma. Int J Mol Sci. 2014; 15: 11294-306. http://doi. org/10.3390/ijms150711294.

31. Zhao S, Li C, Ye YB, Peng F, Chen Q. Expression of chemerin correlates with a favorable prognosis in patients with non-small cell lung cancer. Lab Med. 2011; 42: 553-7. http://doi.org/10.1309/lmww79nits6zadpt.

32. Rourke JL, Muruganandan S, Dranse HJ, McMullen NM, Sinal CJ. Gpr1 is an active chemerin receptor influencing glucose homeostasis in obese mice. J Endocrinol. 2014; 222: 201-15. http://doi.org/10.1530/JOE-14-0069.

33. Zabel BA, Nakae S, Zuniga L, Kim JY, Ohyama T, Alt C, Pan J, Suto H, Soler D, Allen SJ, Handel TM, Song CH, Galli SJ, et al. Mast cell-expressed orphan receptor CCRL2 binds chemerin and is required for optimal induction of IgEmediated passive cutaneous anaphylaxis. J Exp Med. 2008; 205: 2207-20. http://doi.org/10.1084/jem.20080300.

34. Galligan CL, Matsuyama W, Matsukawa A, Mizuta H, Hodge DR, Howard OM, Yoshimura T. Up-regulated expression and activation of the orphan chemokine receptor, CCRL2, in rheumatoid arthritis. Arthritis Rheum. 2004; 50: 1806-14. http://doi.org/10.1002/art.20275.

35. Akram IG, Georges R, Hielscher T, Adwan H, Berger MR. The chemokines CCR1 and CCRL2 have a role in colorectal cancer liver metastasis. Tumour Biol. 2015. http://doi.org/10.1007/s13277-015-4089-4.

36. Sveinbjornsson B, Rasmuson A, Baryawno N, Wan M, Pettersen I, Ponthan F, Orrego A, Haeggstrom JZ, Johnsen JI, Kogner P. Expression of enzymes and receptors of the leukotriene pathway in human neuroblastoma promotes tumor survival and provides a target for therapy. FASEB J. 2008; 22: 3525-36. http://doi.org/10.1096/fj.07-103457.

37. Kaur J, Adya R, Tan BK, Chen J, Randeva HS. Identification of chemerin receptor (ChemR23) in human endothelial cells: chemerin-induced endothelial angiogenesis. Biochem Biophys Res Commun. 2010; 391: 1762-8. http://doi. org/10.1016/j.bbrc.2009.12.150.

38. Barnea G, Strapps W, Herrada G, Berman Y, Ong J, Kloss B, Axel R, Lee KJ. The genetic design of signaling cascades to record receptor activation. Proc Natl Acad Sci U S A. 2008; 105: 64-9. http://doi.org/10.1073/pnas.0710487105.

39. De Henau O, Degroot GN, Imbault V, Robert V, De Poorter C, McHeik S, Gales C, Parmentier M, Springael JY. Signaling properties of chemerin receptors CMKLR1, GPR1 and CCRL2. PLoS One. 2016; 11: e0164179. http:// doi.org/10.1371/journal.pone.0164179.

40. Rourke JL, Dranse HJ, Sinal CJ. CMKLR1 and GPR1 mediate chemerin signaling through the RhoA/ROCK 
pathway. Mol Cell Endocrinol. 2015; 417: 36-51. http://doi. org/10.1016/j.mce.2015.09.002.

41. Kumar JD, Kandola S, Tiszlavicz L, Reisz Z, Dockray GJ, Varro A. The role of chemerin and ChemR23 in stimulating the invasion of squamous oesophageal cancer cells. $\mathrm{Br}$ J Cancer. 2016; 114: 1152-9. http://doi.org/10.1038/ bjc. 2016.93 .

42. Graham KL, Zhang JV, Lewen S, Burke TM, Dang T, Zoudilova M, Sobel RA, Butcher EC, Zabel BA. A novel CMKLR1 small molecule antagonist suppresses CNS autoimmune inflammatory disease. PLoS One. 2014; 9: e112925. http://doi.org/10.1371/journal.pone.0112925.

43. Brodeur GM, Iyer R, Croucher JL, Zhuang T, Higashi M, Kolla V. Therapeutic targets for neuroblastomas. Expert Opin Ther Targets. 2014; 18: 277-92. http://doi.org/10.151 7/14728222.2014.867946.

44. Chow MT, Luster AD. Chemokines in cancer. Cancer Immunol Res. 2014; 2: 1125-31. http://doi. org/10.1158/2326-6066.CIR-14-0160.

45. Zhou J, Xiang Y, Yoshimura T, Chen K, Gong W, Huang J, Zhou Y, Yao X, Bian X, Wang JM. The role of chemoattractant receptors in shaping the tumor microenvironment. Biomed Res Int. 2014; 2014: 751392. http://doi.org/10.1155/2014/751392.

46. Gross N, Meier R. Chemokines in neuroectodermal cancers: the crucial growth signal from the soil. Semin Cancer Biol. 2009; 19: 103-10. http://doi.org/10.1016/j. semcancer.2008.10.009.

47. Bondue B, Wittamer V, Parmentier M. Chemerin and its receptors in leukocyte trafficking, inflammation and metabolism. Cytokine Growth Factor Rev. 2011; 22: 331-8. http://doi.org/10.1016/j.cytogfr.2011.11.004.

48. Zhao W, Xu Y, Xu J, Wu D, Zhao B, Yin Z, Wang X. Subsets of myeloid-derived suppressor cells in hepatocellular carcinoma express chemokines and chemokine receptors differentially. Int Immunopharmacol. 2015; 26: 314-21. http://doi.org/10.1016/j.intimp.2015.04.010.

49. Chua SK, Shyu KG, Lin YF, Lo HM, Wang BW, Chang H, Lien LM. Tumor necrosis factor-alpha and the ERK pathway drive chemerin expression in response to hypoxia in cultured human coronary artery endothelial cells. PLoS One. 2016; 11: e0165613. http://doi.org/10.1371/journal. pone. 0165613 .

50. Rama D, Esendagli G, Guc D. Expression of chemokinelike receptor 1 (CMKLR1) on J744A.1 macrophages co-cultured with fibroblast and/or tumor cells: modeling the influence of microenvironment. Cell Immunol. 2011; 271: 134-40. http://doi.org/10.1016/j.cellimm.2011.06.016.

51. Singh A, Ruan Y, Tippett T, Narendran A. Targeted inhibition of MEK1 by cobimetinib leads to differentiation and apoptosis in neuroblastoma cells. J Exp Clin Cancer Res. 2015; 34: 104. http://doi.org/10.1186/ s13046-015-0222-x.
52. Vieira GC, Chockalingam S, Melegh Z, Greenhough A, Malik S, Szemes M, Park JH, Kaidi A, Zhou L, Catchpoole D, Morgan R, Bates DO, Gabb PD, et al. LGR5 regulates pro-survival MEK/ERK and proliferative Wnt/beta-catenin signalling in neuroblastoma. Oncotarget. 2015; 6: 4005367. http://doi.org/10.18632/oncotarget.5548.

53. Johnsen JI, Segerstrom L, Orrego A, Elfman L, Henriksson M, Kagedal B, Eksborg S, Sveinbjornsson B, Kogner P. Inhibitors of mammalian target of rapamycin downregulate MYCN protein expression and inhibit neuroblastoma growth in vitro and in vivo. Oncogene. 2008; 27: 2910-22. http://doi.org/10.1038/sj.onc.1210938.

54. King D, Yeomanson D, Bryant HE. PI3King the lock: targeting the PI3K/Akt/mTOR pathway as a novel therapeutic strategy in neuroblastoma. J Pediatr Hematol Oncol. 2015; 37: 245-51. http://doi.org/10.1097/MPH.0000000000000329.

55. Banas M, Zegar A, Kwitniewski M, Zabieglo K, Marczynska J, Kapinska-Mrowiecka M, LaJevic M, Zabel BA, Cichy J. The expression and regulation of chemerin in the epidermis. PLoS One. 2015; 10: e0117830. http://doi. org/10.1371/journal.pone.0117830.

56. Hadler-Olsen E, Winberg JO, Uhlin-Hansen L. Matrix metalloproteinases in cancer: their value as diagnostic and prognostic markers and therapeutic targets. Tumour Biol. 2013; 34: 2041-51. http://doi.org/10.1007/ s13277-013-0842-8.

57. Ribatti D, Surico G, Vacca A, De Leonardis F, Lastilla G, Montaldo PG, Rigillo N, Ponzoni M. Angiogenesis extent and expression of matrix metalloproteinase-2 and -9 correlate with progression in human neuroblastoma. Life Sci. 2001; 68: 1161-8.

58. Ara T, Fukuzawa M, Kusafuka T, Komoto Y, Oue T, Inoue M, Okada A. Immunohistochemical expression of MMP-2, MMP-9, and TIMP-2 in neuroblastoma: association with tumor progression and clinical outcome. J Pediatr Surg. 1998; 33: 1272-8.

59. Figenschau Y, Knutsen G, Shahazeydi S, Johansen O, Sveinbjornsson B. Human articular chondrocytes express functional leptin receptors. Biochem Biophys Res Commun. 2001; 287: 190-7. http://doi.org/10.1006/bbrc.2001.5543.

60. Schindelin J, Arganda-Carreras I, Frise E, Kaynig V, Longair M, Pietzsch T, Preibisch S, Rueden C, Saalfeld S, Schmid B, Tinevez JY, White DJ, Hartenstein V, et al. Fiji: an open-source platform for biological-image analysis. Nat Methods. 2012; 9: 676-82. http://doi.org/10.1038/ nmeth.2019.

61. Malla N, Berg E, Uhlin-Hansen L, Winberg JO. Interaction of pro-matrix metalloproteinase-9/proteoglycan heteromer with gelatin and collagen. J Biol Chem. 2008; 283: 1365265. http://doi.org/10.1074/jbc.M709140200.

62. Mathisen B, Lindstad RI, Hansen J, El-Gewely SA, Maelandsmo GM, Hovig E, Fodstad O, Loennechen T, Winberg JO. S100A4 regulates membrane induced 
activation of matrix metalloproteinase- 2 in osteosarcoma cells. Clin Exp Metastasis. 2003; 20: 701-11.

63. Mosmann T. Rapid colorimetric assay for cellular growth and survival: application to proliferation and cytotoxicity assays. J Immunol Methods. 1983; 65: 55-63.
64. Hather G, Liu R, Bandi S, Mettetal J, Manfredi M, Shyu WC, Donelan J, Chakravarty A. Growth rate analysis and efficient experimental design for tumor xenograft studies. Cancer Inform. 2014; 13: 65-72. http://doi.org/10.4137/ CIN.S13974. 